Design, Synthesis, and Bioactivities of Phthalide and Coumarin Derivatives based on the Biosynthesis and Structure

\title{
Simplification of Gossypol
}

Dedicated to the 100th anniversary of Chemistry at Nankai University

Zhonglin Guo, ${ }^{1 \#}$ Pan Zhou, ${ }^{1 \#}$ Hongjian Song, ${ }^{1 *}$ Yuxiu Liu, ${ }^{1}$ Jingjing Zhang,,${ }^{12 *}$ Yongqiang $\mathrm{Li},{ }^{1}$ and Qingmin Wang ${ }^{1 *}$

${ }^{1}$ State Key Laboratory of Elemento-Organic Chemistry, College of Chemistry, Frontiers Science Center for New Organic Matter, Nankai University, Tianjin 300071, China

${ }^{2}$ College of Basic Science, Tianjin Agricultural University, Tianjin 300384, China 


\section{Table of Contents}

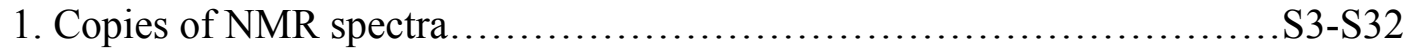

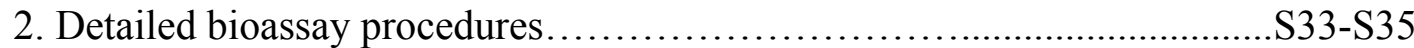




\section{Copies of NMR spectra}

4a ${ }^{1} \mathrm{H}$ NMR (400 MHz, $\left.\mathrm{CDCl}_{3}\right)$

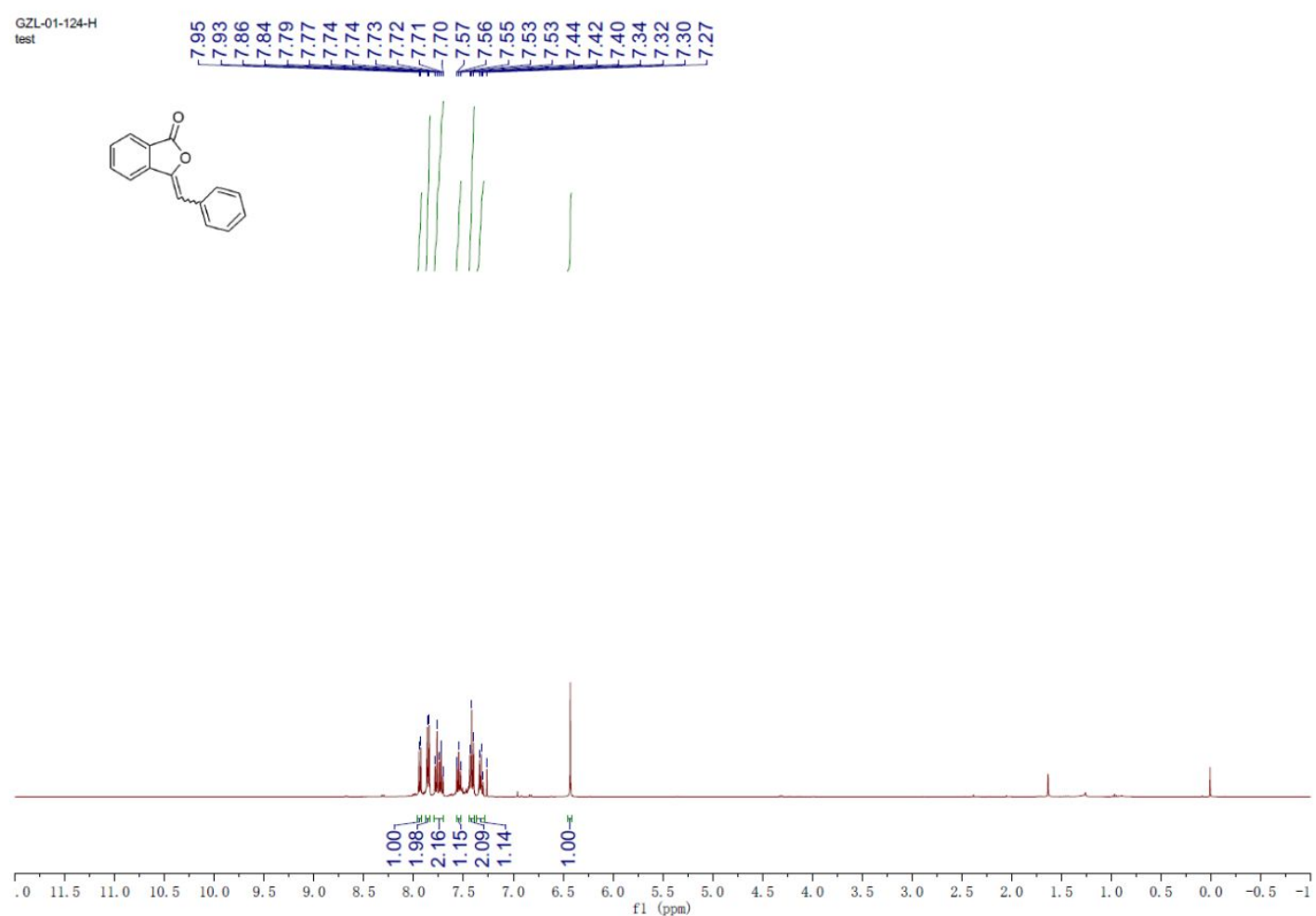

4a ${ }^{13} \mathrm{C}$ NMR (100 MHz, $\left.\mathrm{CDCl}_{3}\right)$ 
GZL-01-124-C
test

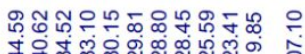

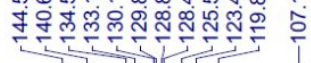

menco

준

(N)

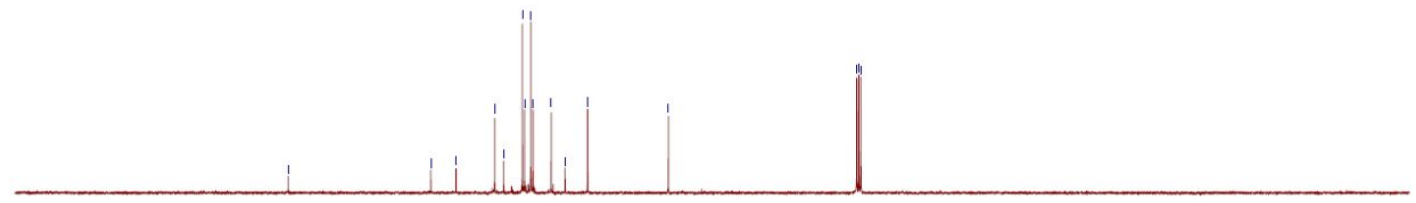

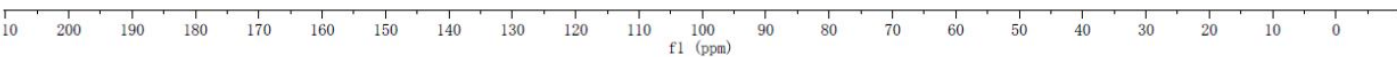


4b ${ }^{1} \mathrm{H}$ NMR (400 MHz, $\mathrm{CDCl}_{3}$ )

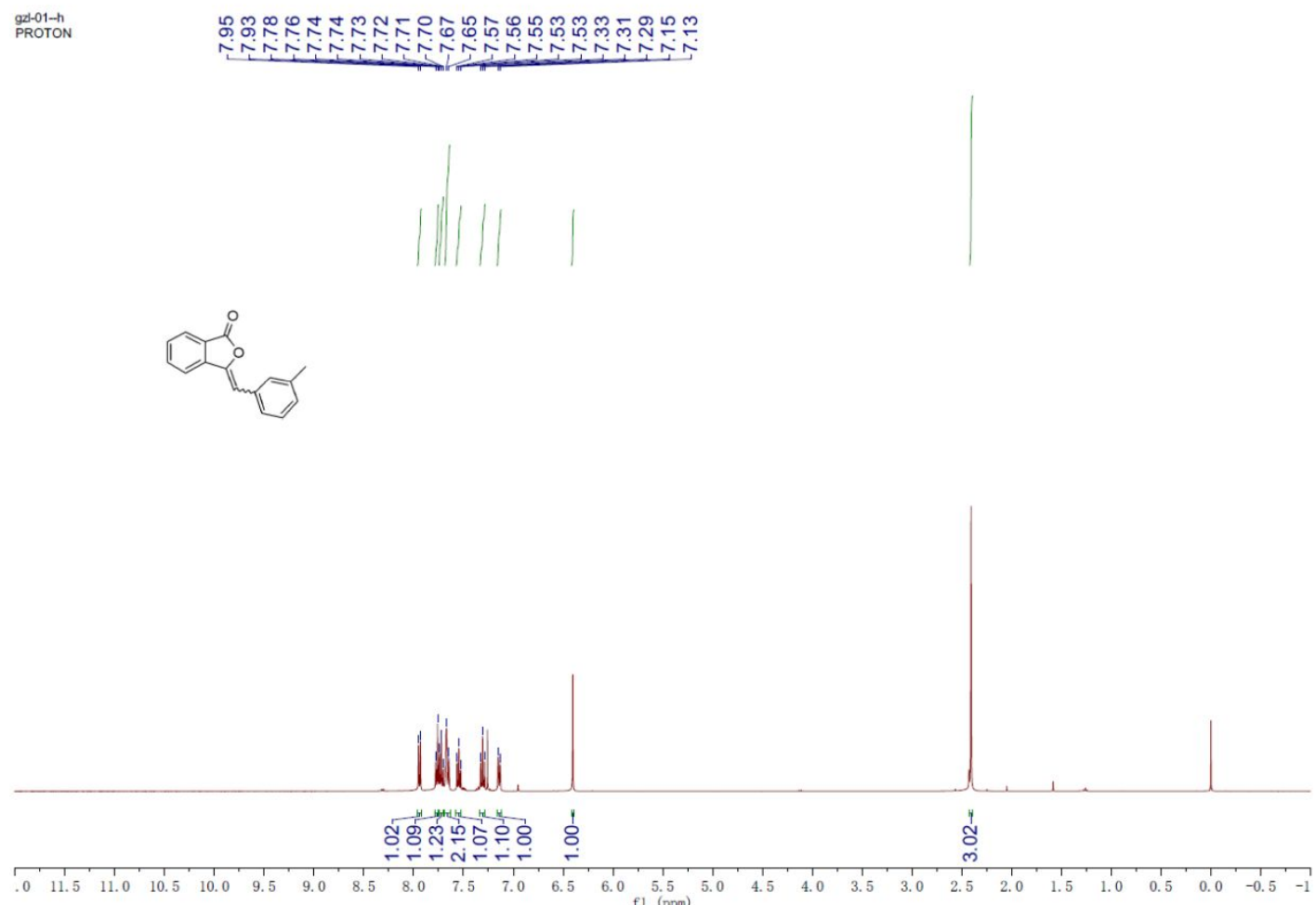

4b ${ }^{13} \mathrm{C}$ NMR (100 MHz, $\left.\mathrm{CDCl}_{3}\right)$
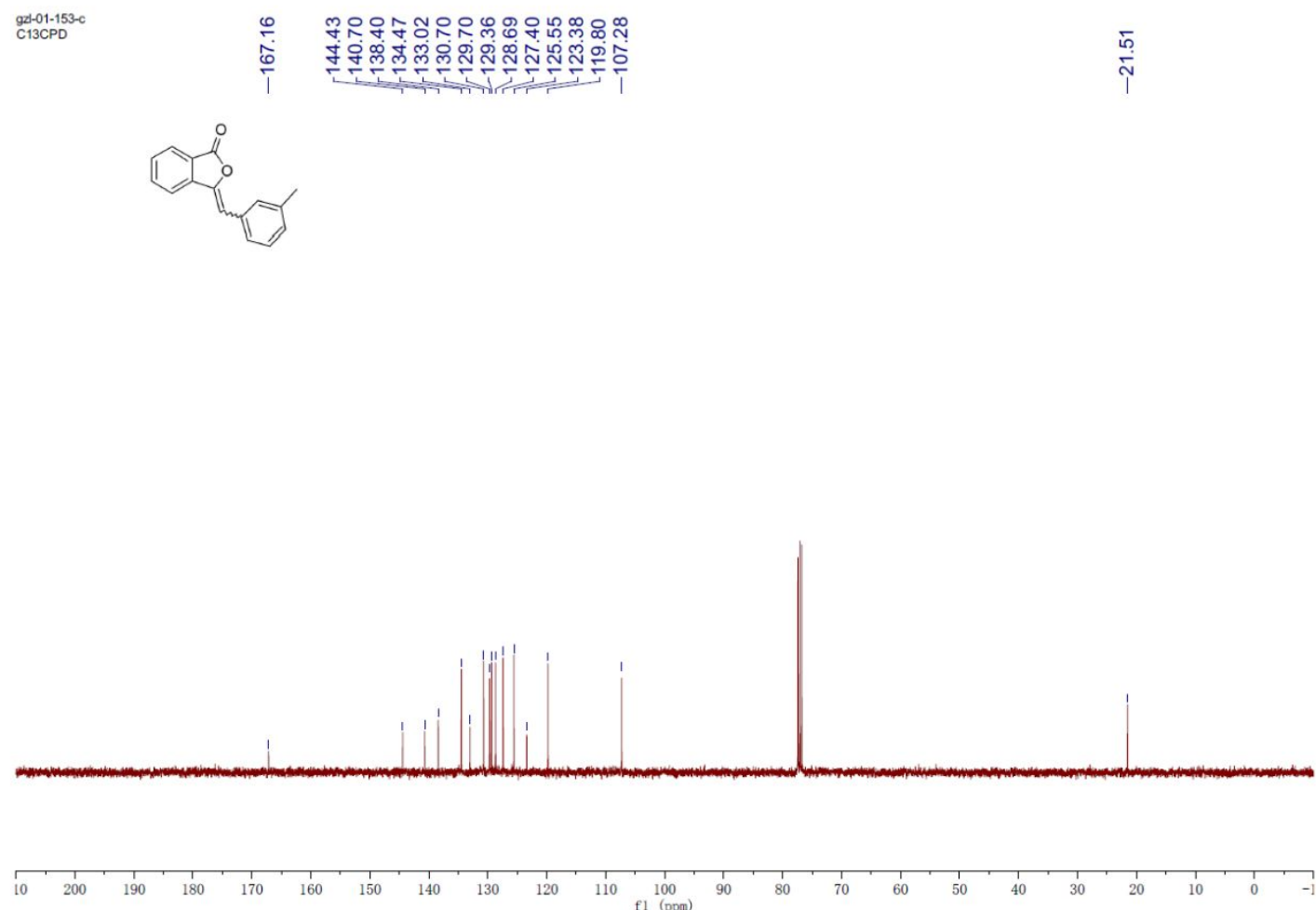
4c ${ }^{1} \mathrm{H}$ NMR (400 MHz, $\left.\mathrm{CDCl}_{3}\right)$

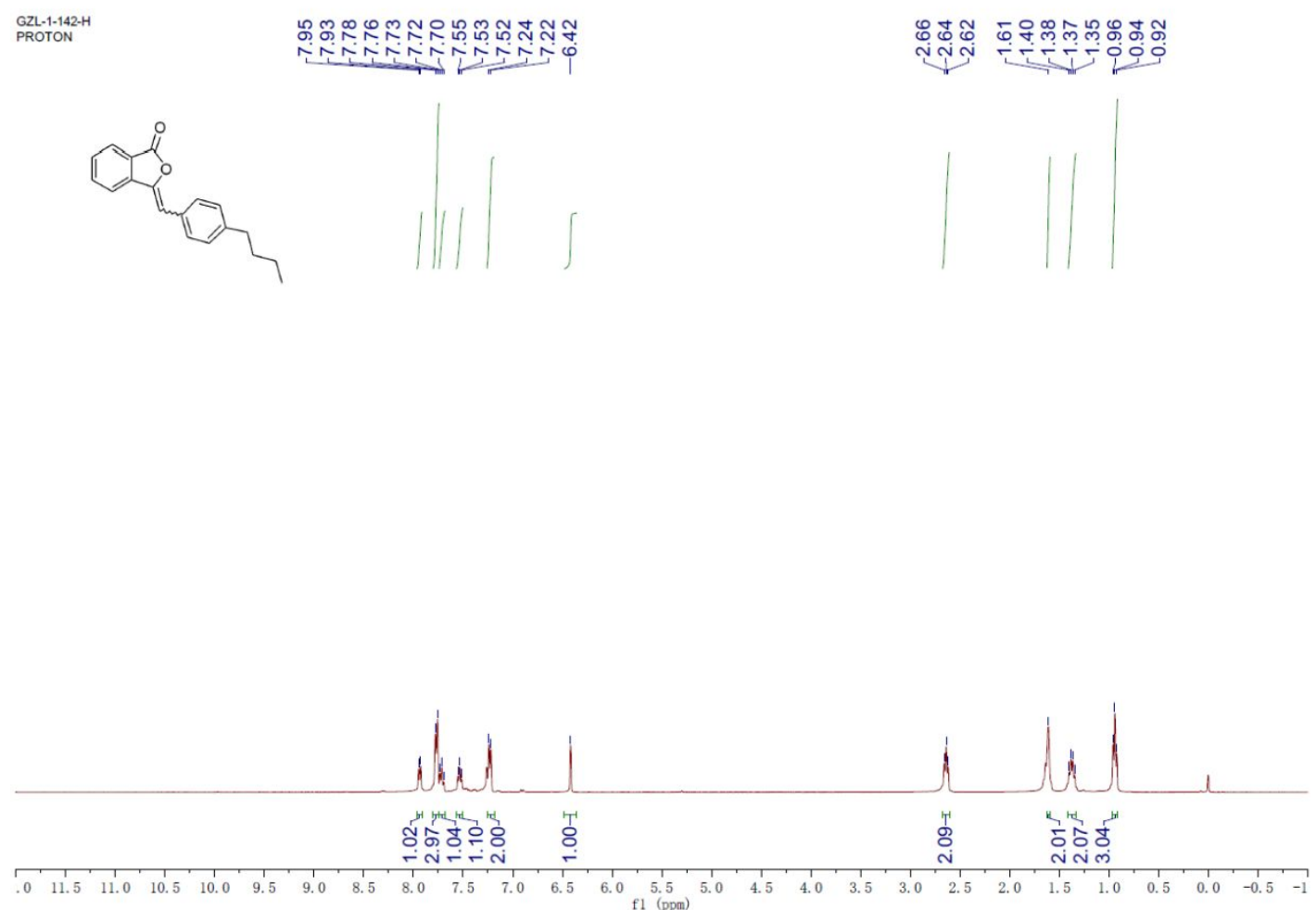

4c ${ }^{13} \mathrm{C}$ NMR $\left(100 \mathrm{MHz}, \mathrm{CDCl}_{3}\right)$
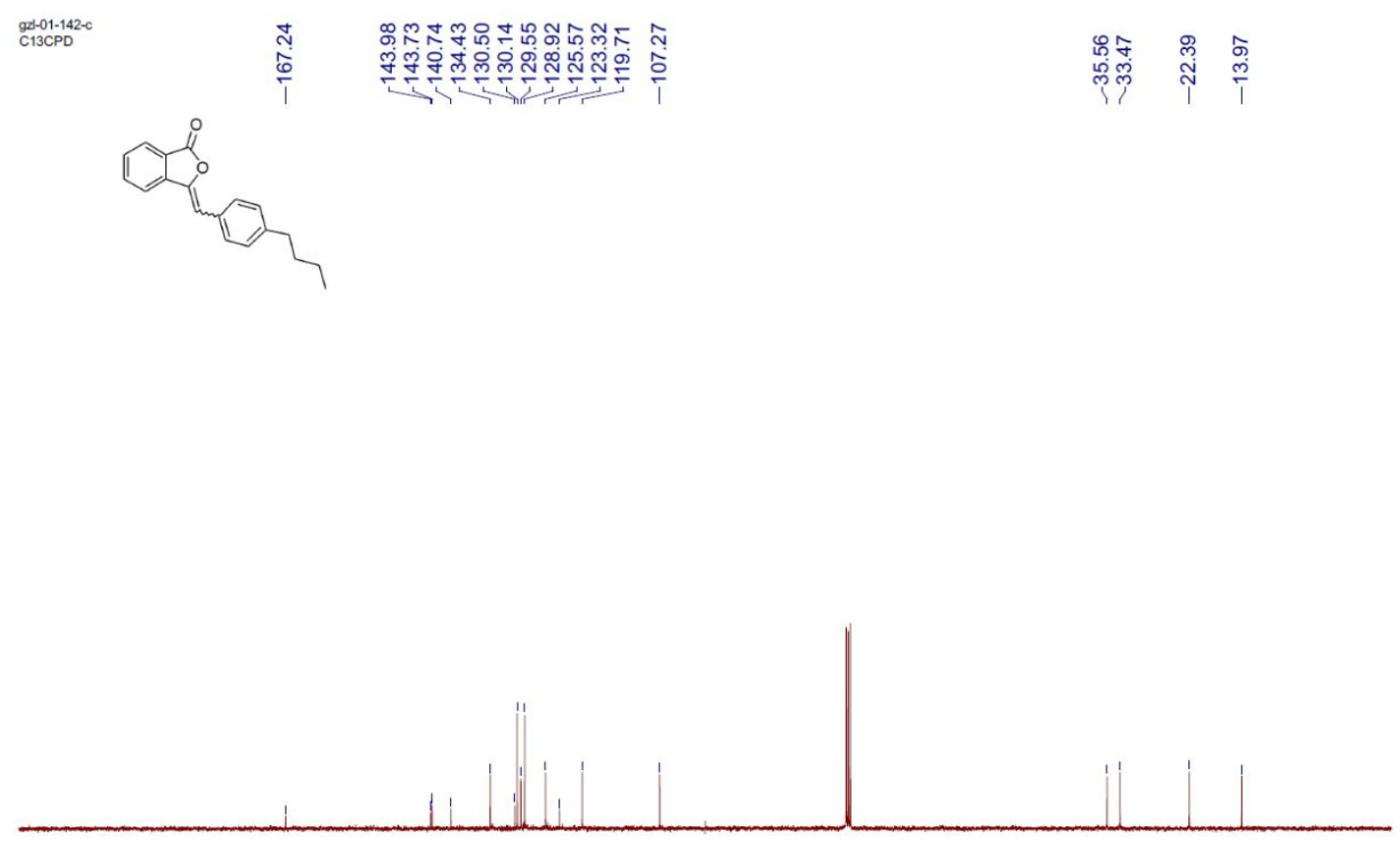

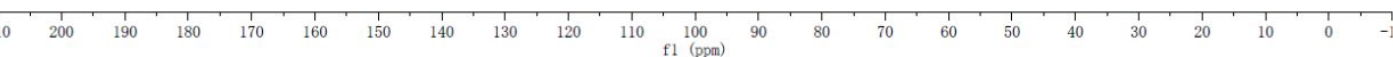


4d ${ }^{1} \mathrm{H}$ NMR (400 MHz, $\mathrm{CDCl}_{3}$ )

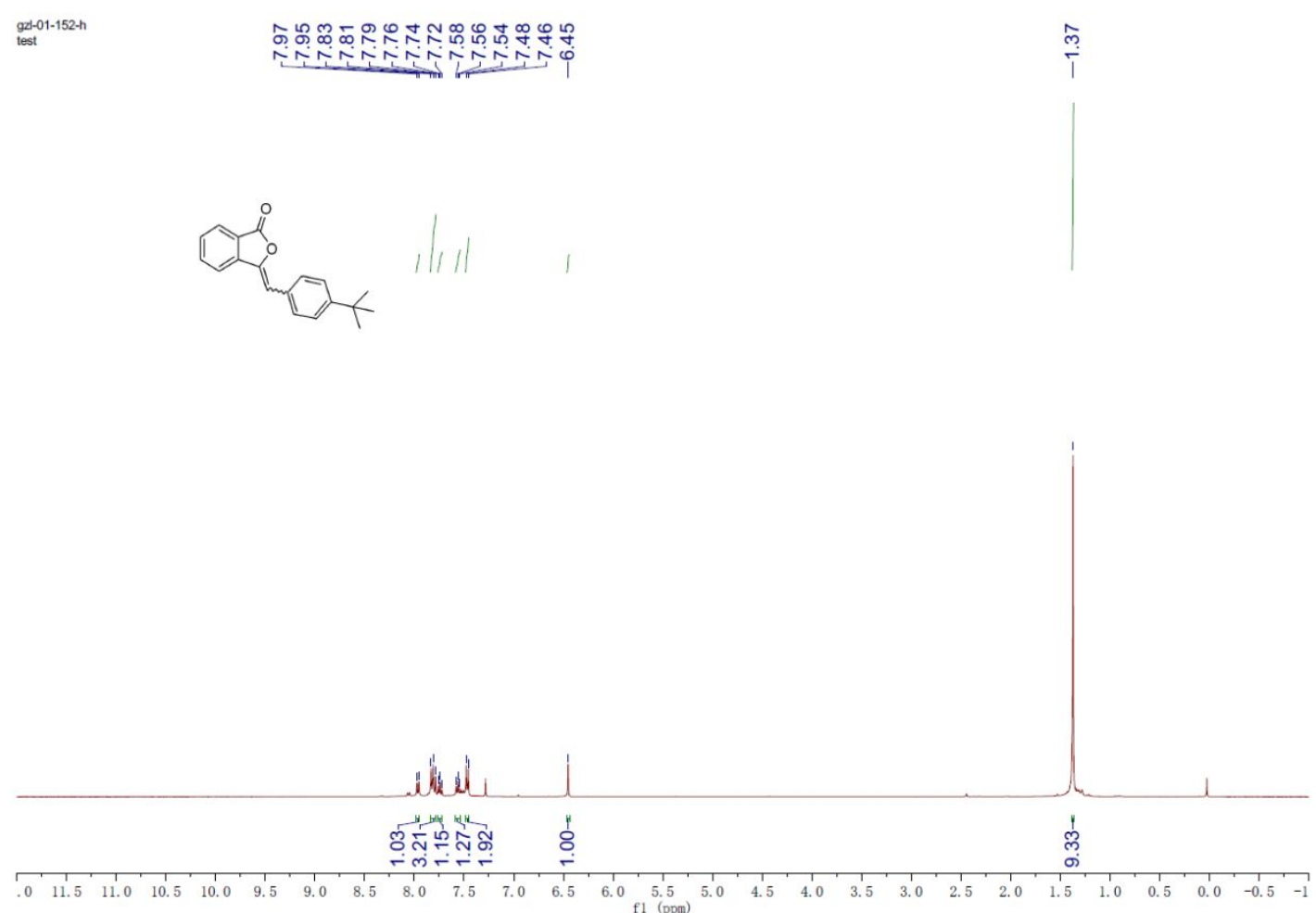

4d ${ }^{13} \mathrm{C}$ NMR (100 MHz, $\left.\mathrm{CDCl}_{3}\right)$

$\substack{\text { ges-101-152-0 } \\ \text { test }}^{2}$

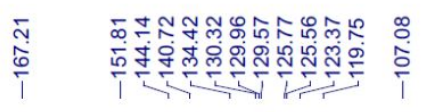

कำ
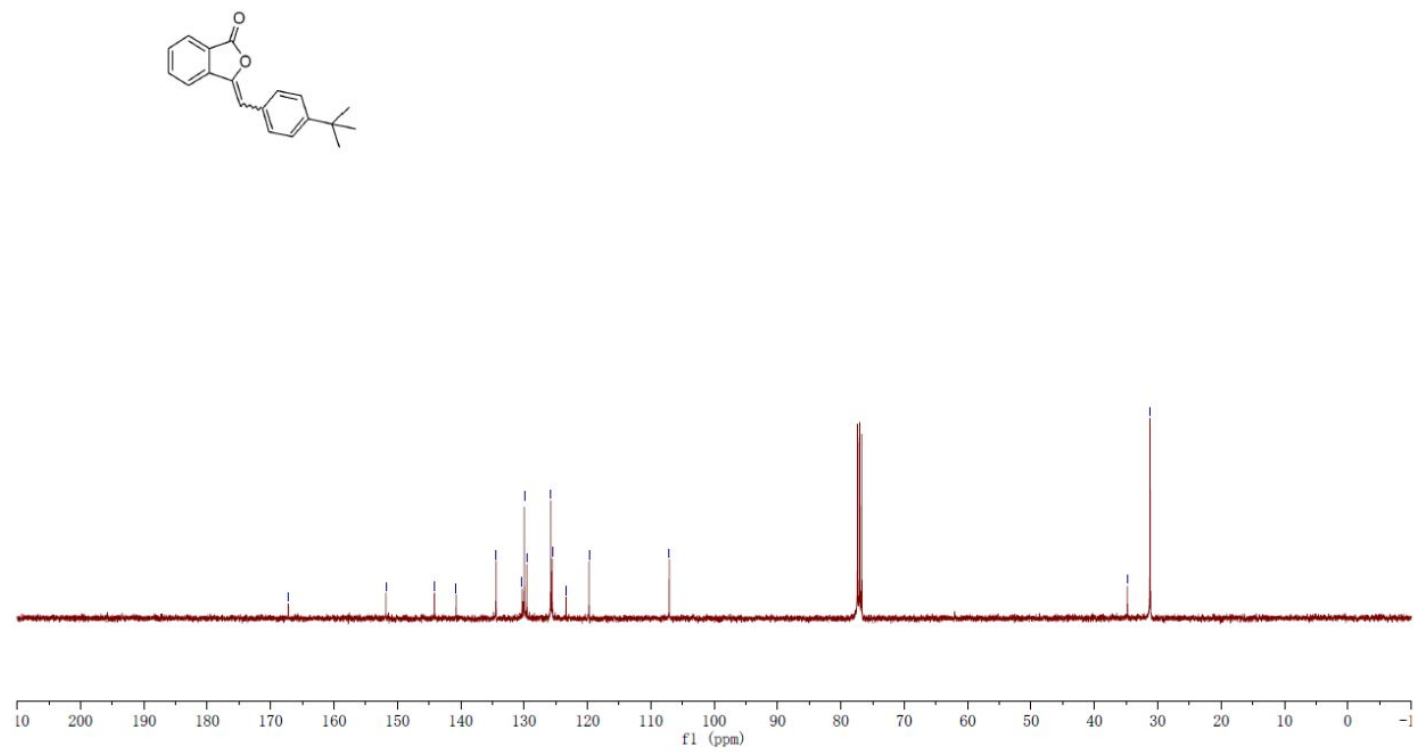
Ae ${ }^{1} \mathrm{H}$ NMR (400 MHz, $\left.\mathrm{CDCl}_{3}\right)$

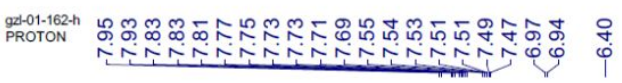
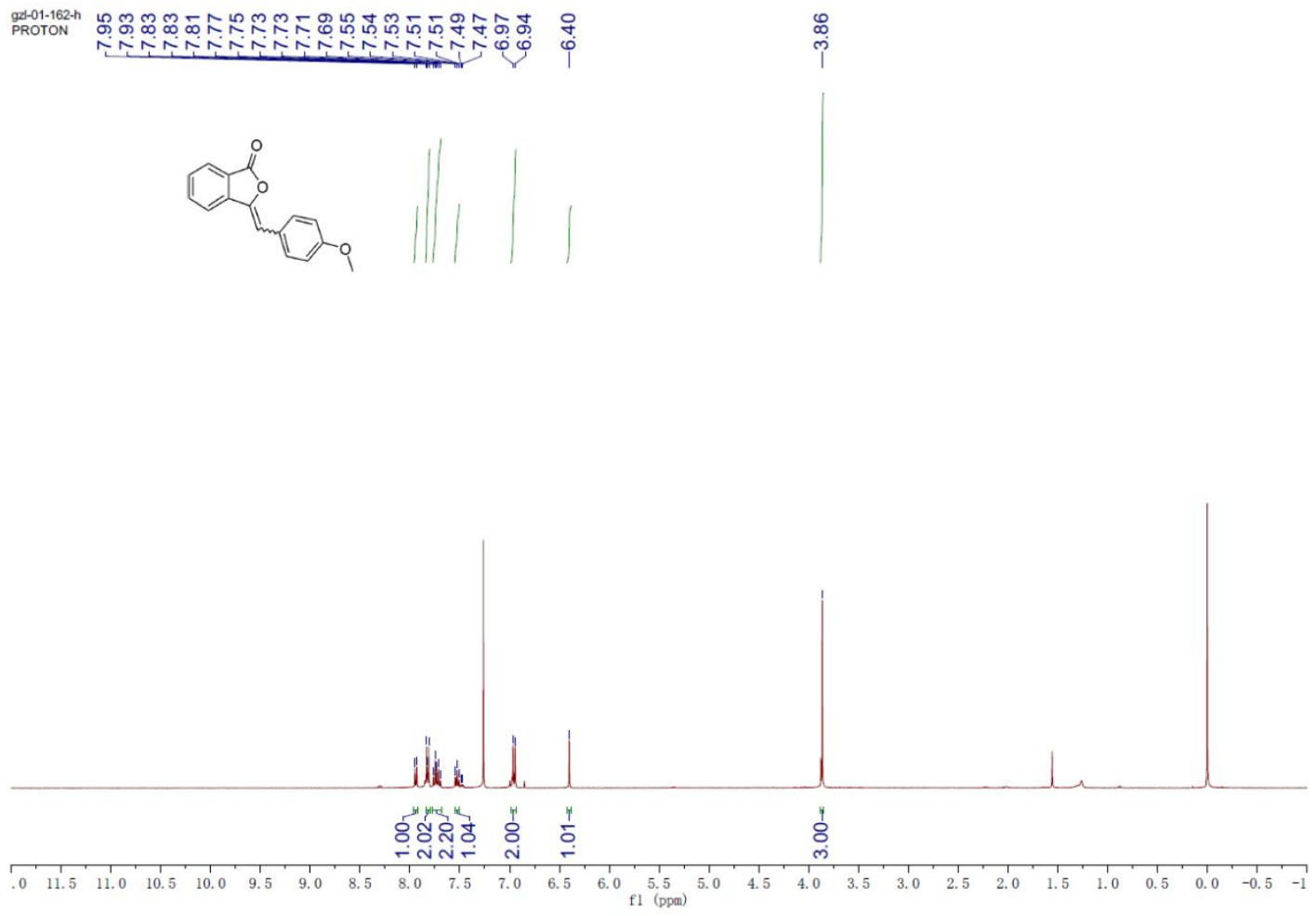

4e ${ }^{13} \mathrm{C}$ NMR (100 MHz, $\left.\mathrm{CDCl}_{3}\right)$

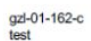

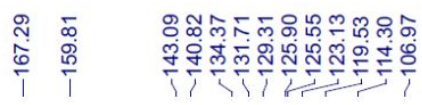

色
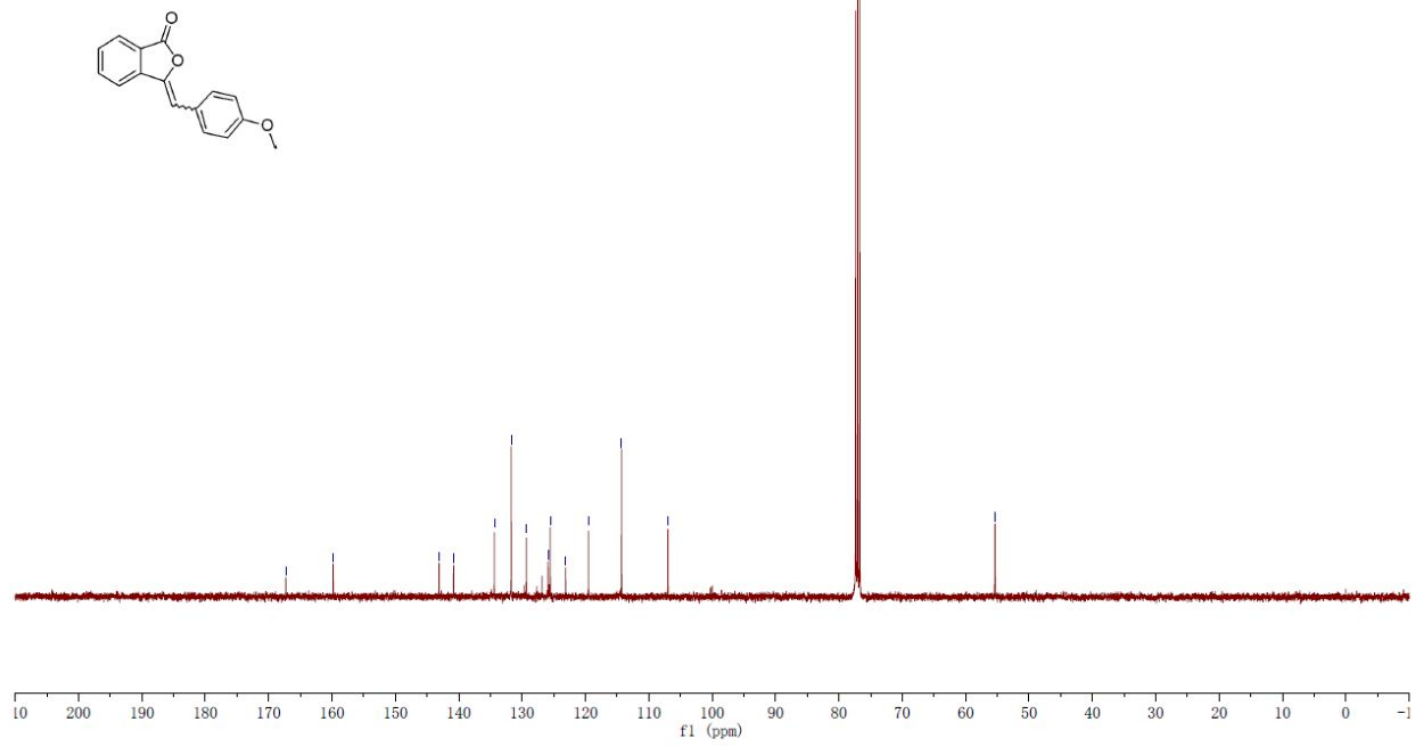

sq 
4f ${ }^{1} \mathrm{H}$ NMR (400 MHz, $\mathrm{CDCl}_{3}$ )

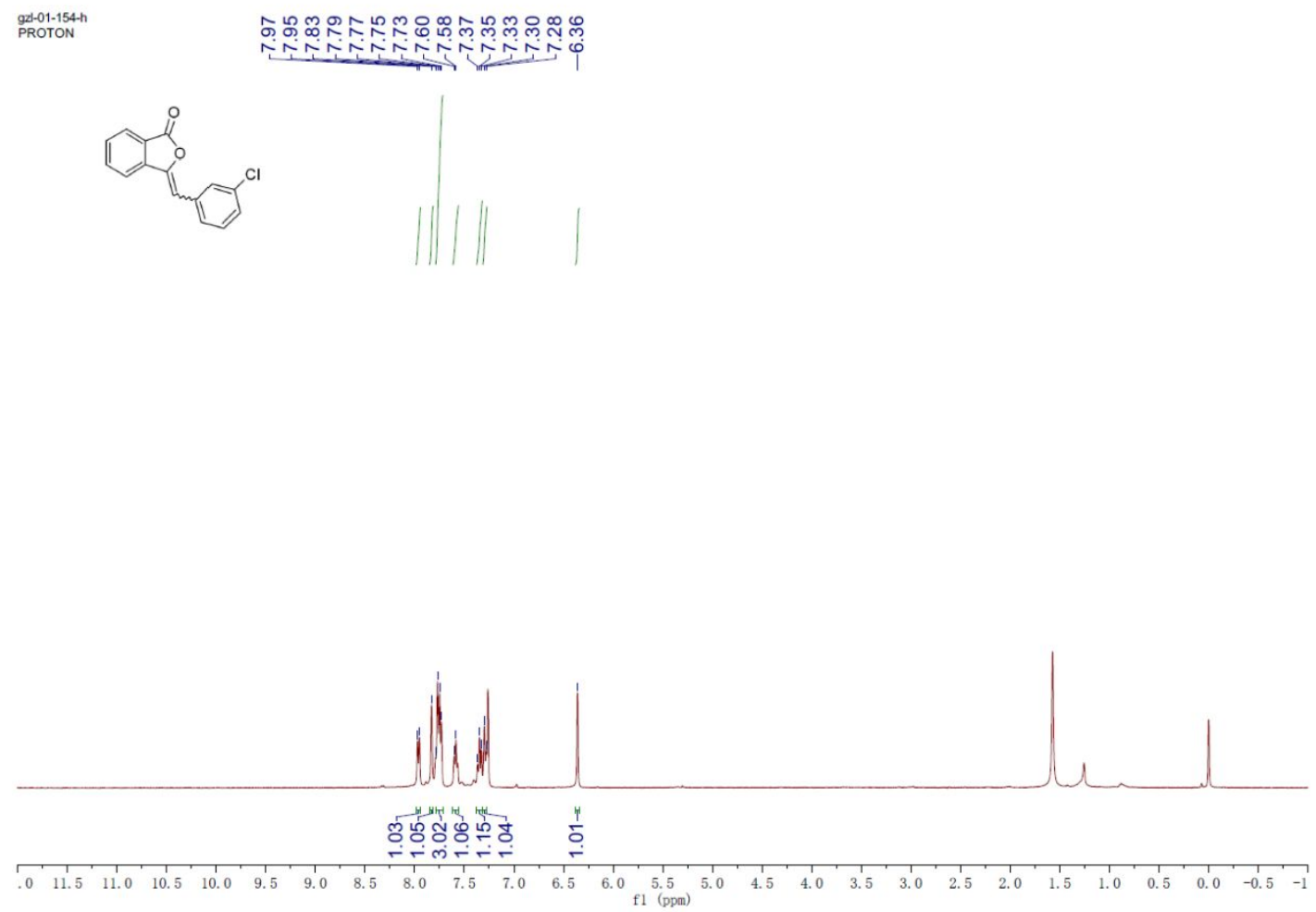

4f ${ }^{13} \mathrm{C}$ NMR $\left(100 \mathrm{MHz}, \mathrm{CDCl}_{3}\right)$
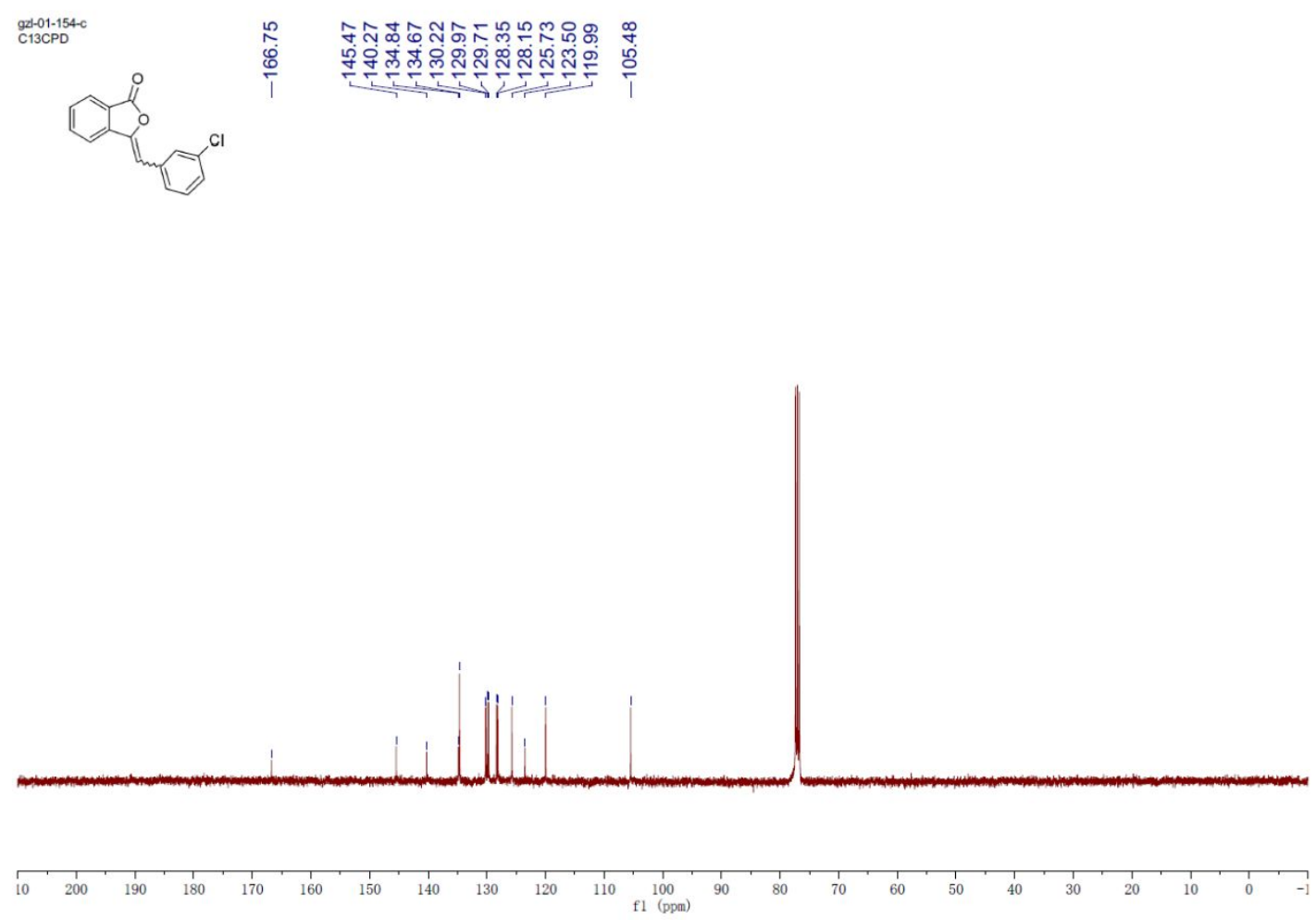
4g ${ }^{1} \mathrm{H}$ NMR (400 MHz, $\mathrm{CDCl}_{3}$ )

$\mathrm{H}+1-1-181-3-1-1$

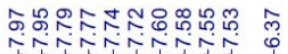
永
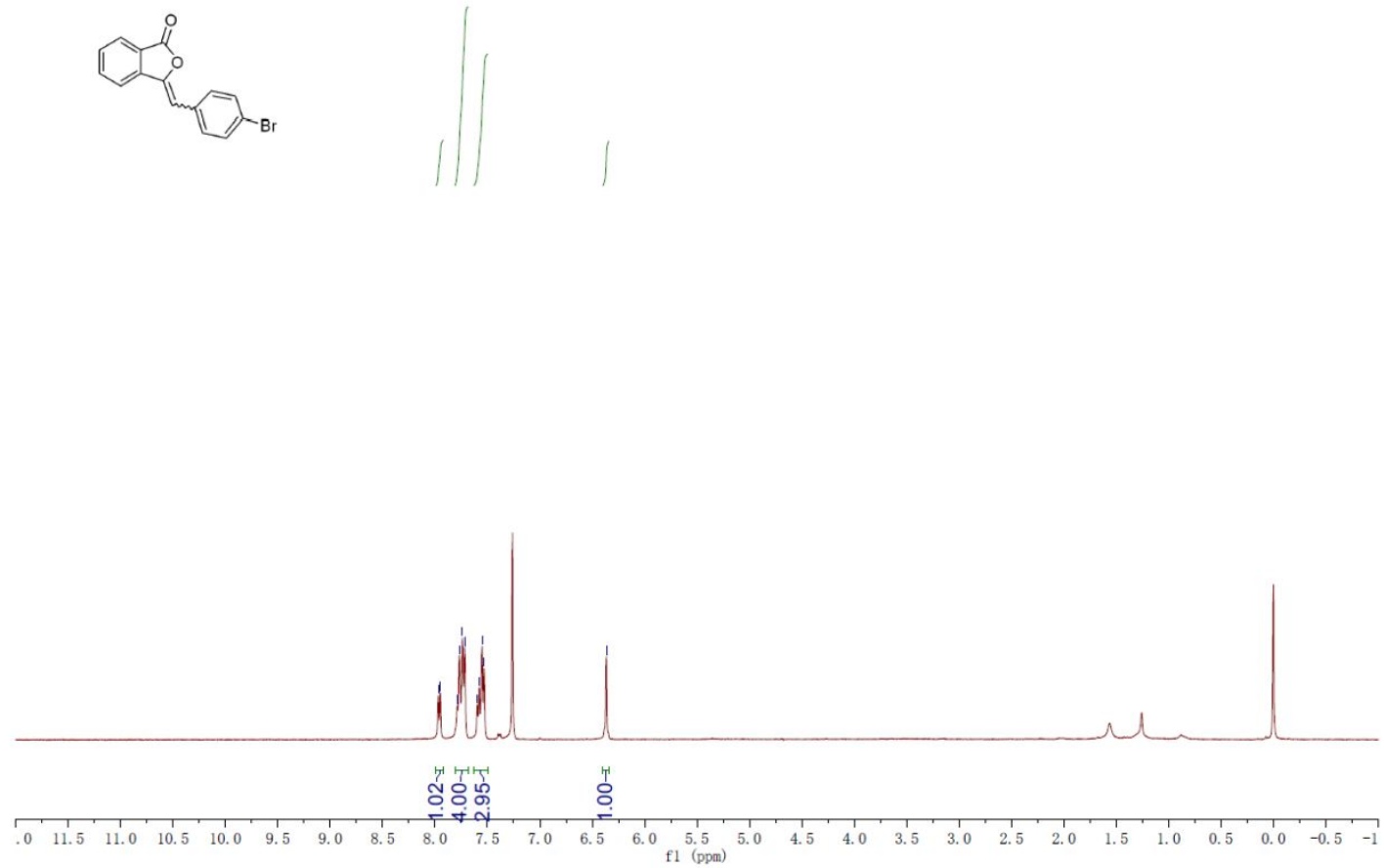

4g ${ }^{13} \mathrm{C}$ NMR $\left(100 \mathrm{MHz}, \mathrm{CDCl}_{3}\right)$

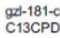

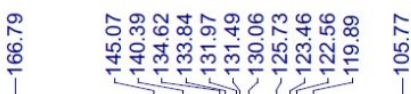<smiles>O=C1OC(=Cc2ccc(Br)cc2)c2ccccc21</smiles>
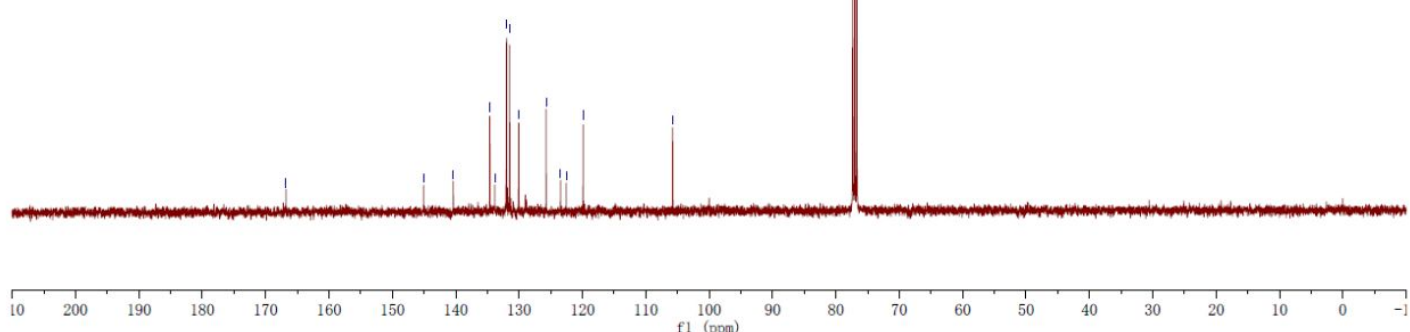
4h ${ }^{1} \mathrm{H}$ NMR (400 MHz, $\mathrm{CDCl}_{3}$ )

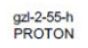

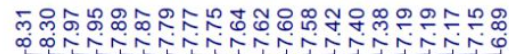<smiles>O=C(c1ccccc1)C1CC2CCC1C2</smiles>
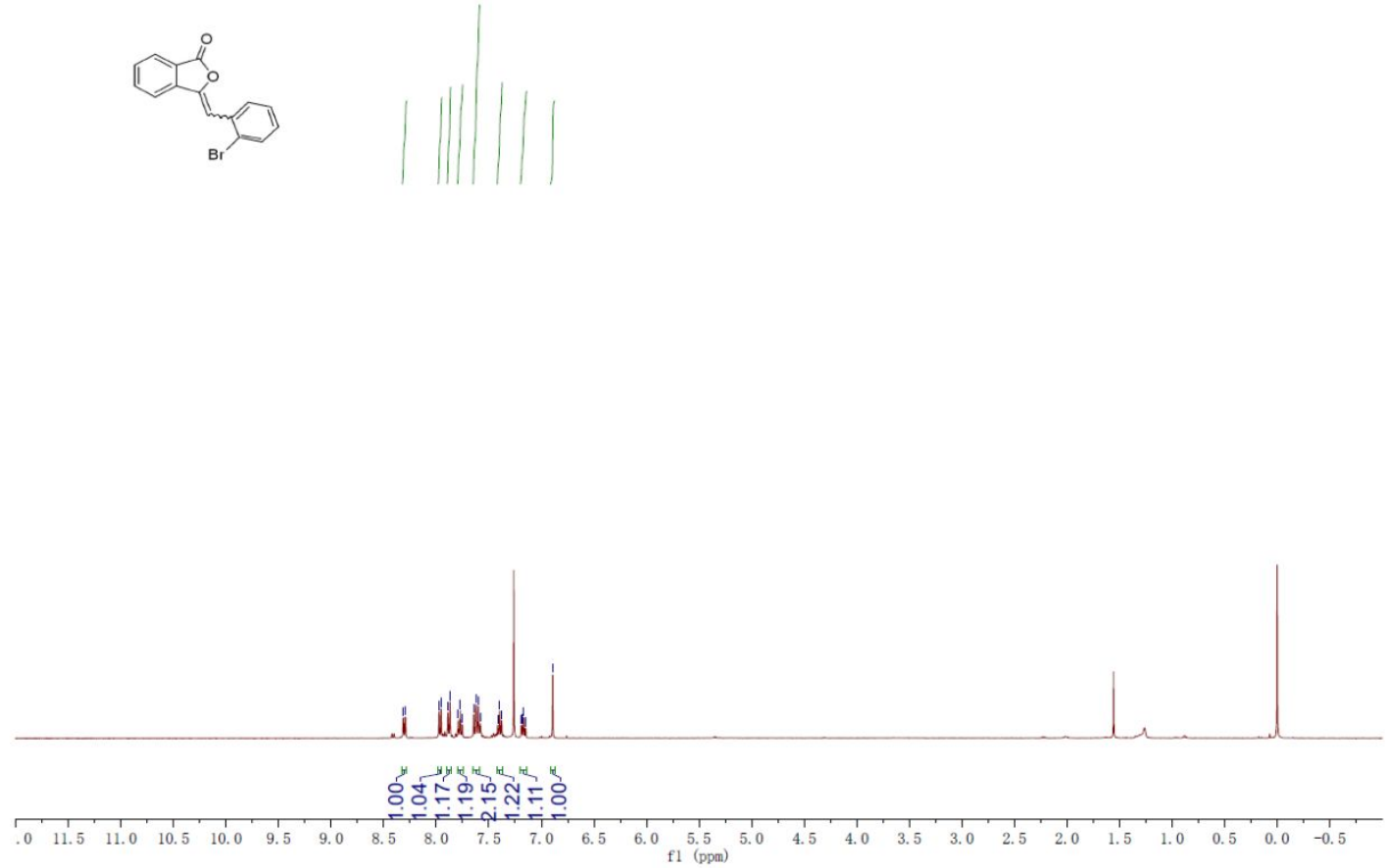

4h ${ }^{13} \mathrm{C}$ NMR $\left(100 \mathrm{MHz}, \mathrm{CDCl}_{3}\right)$
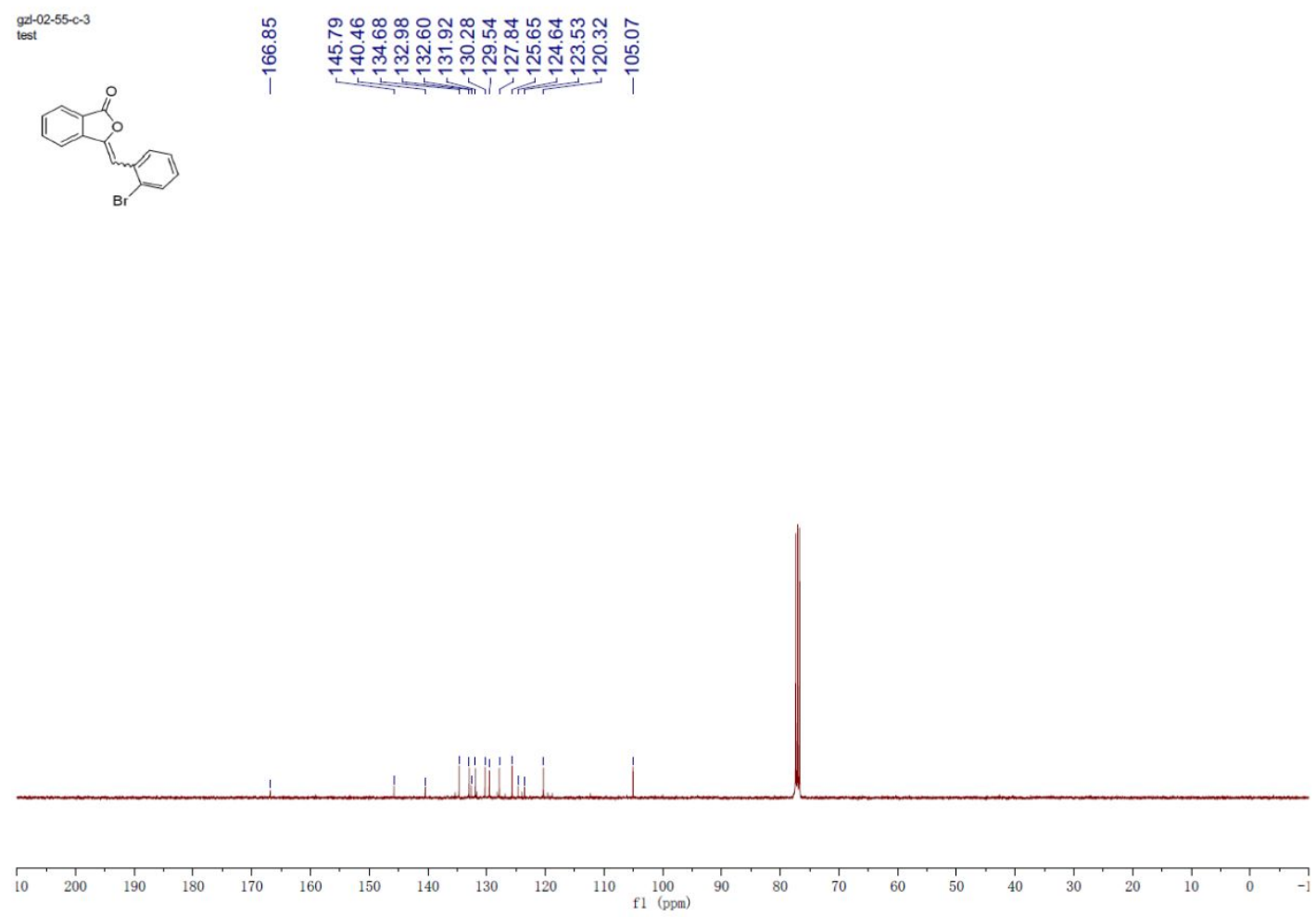
4i ${ }^{1} \mathrm{H}$ NMR (400 MHz, $\mathrm{CDCl}_{3}$ )

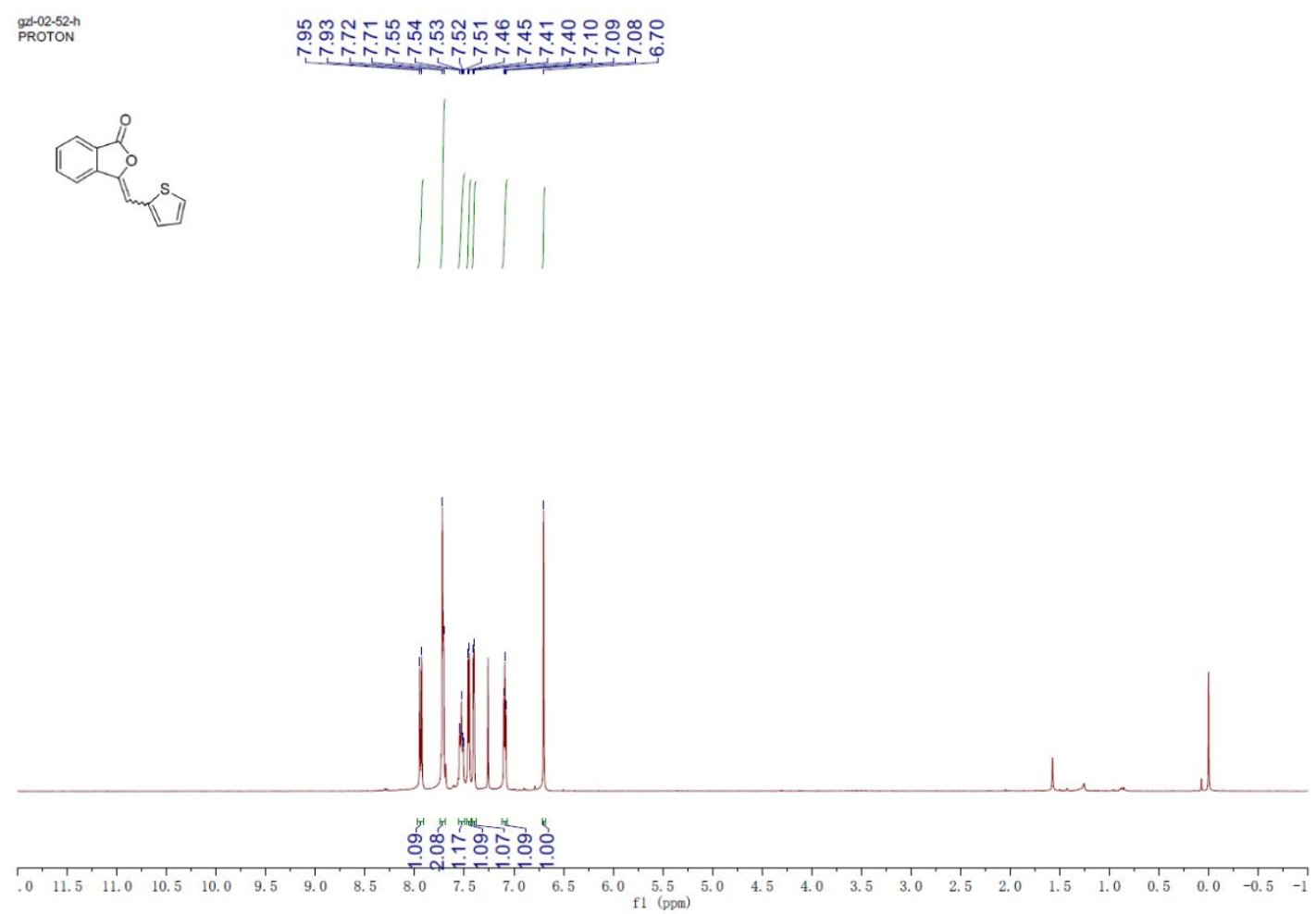

4i ${ }^{13} \mathrm{C} \mathrm{NMR}\left(100 \mathrm{MHz}, \mathrm{CDCl}_{3}\right)$
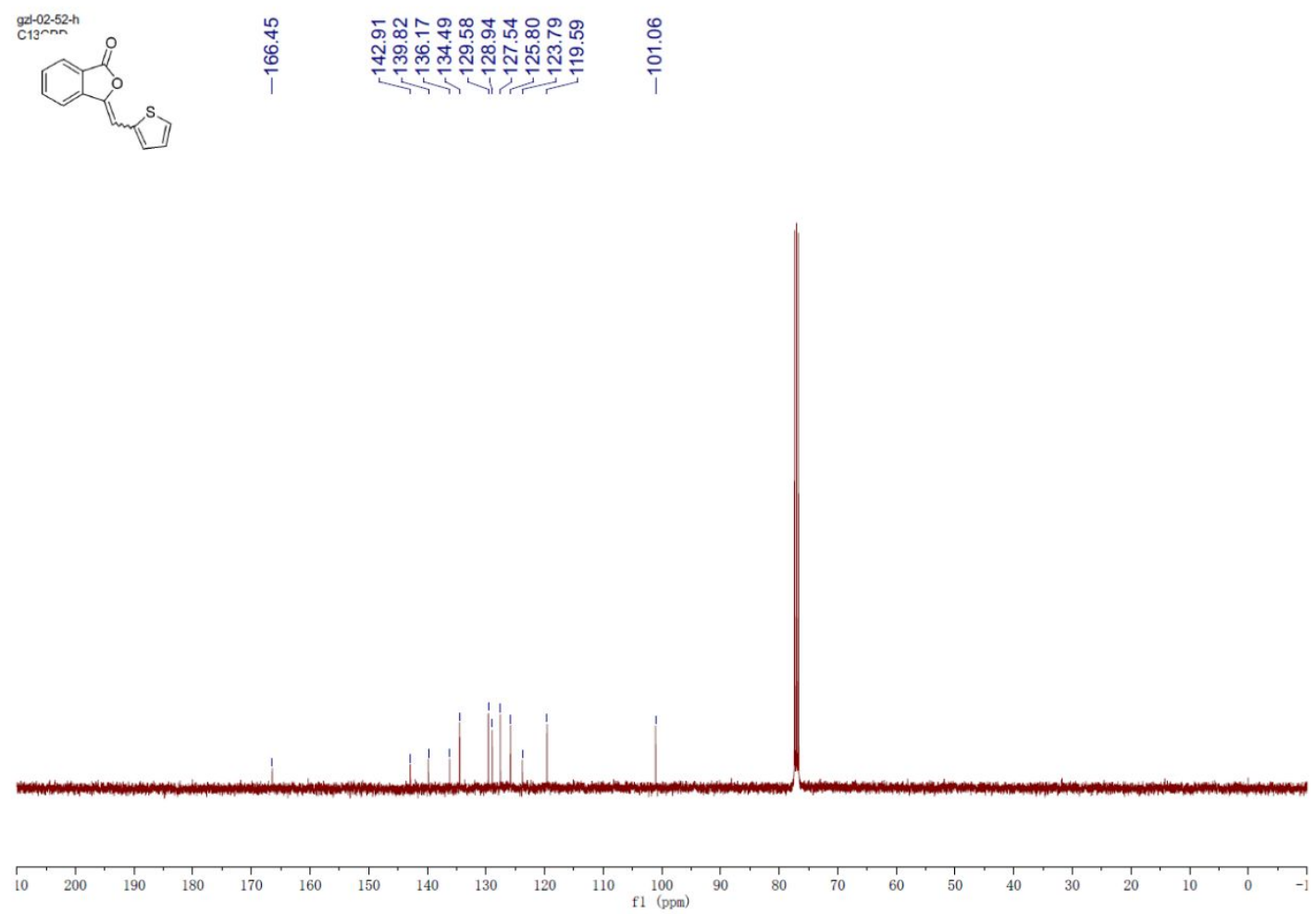
4j ${ }^{1} \mathrm{H}$ NMR (400 MHz, $\mathrm{CDCl}_{3}$ )

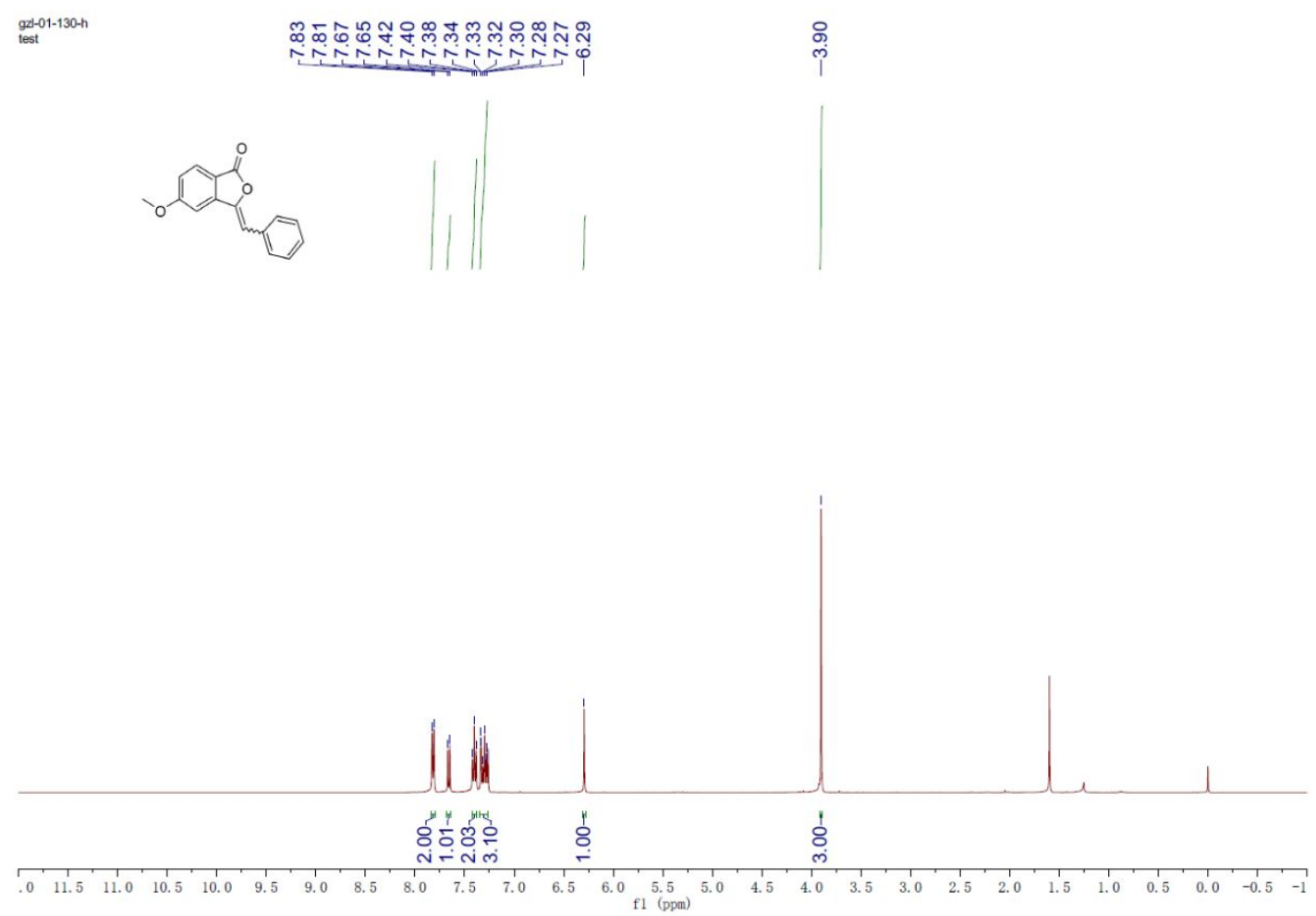

4j ${ }^{13} \mathrm{C} \mathrm{NMR}\left(100 \mathrm{MHz}, \mathrm{CDCl}_{3}\right)$

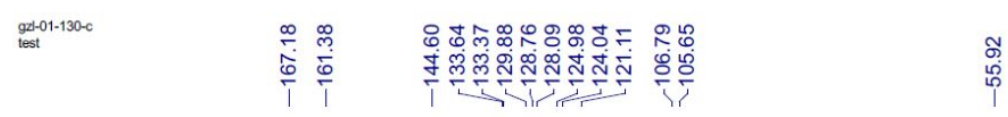
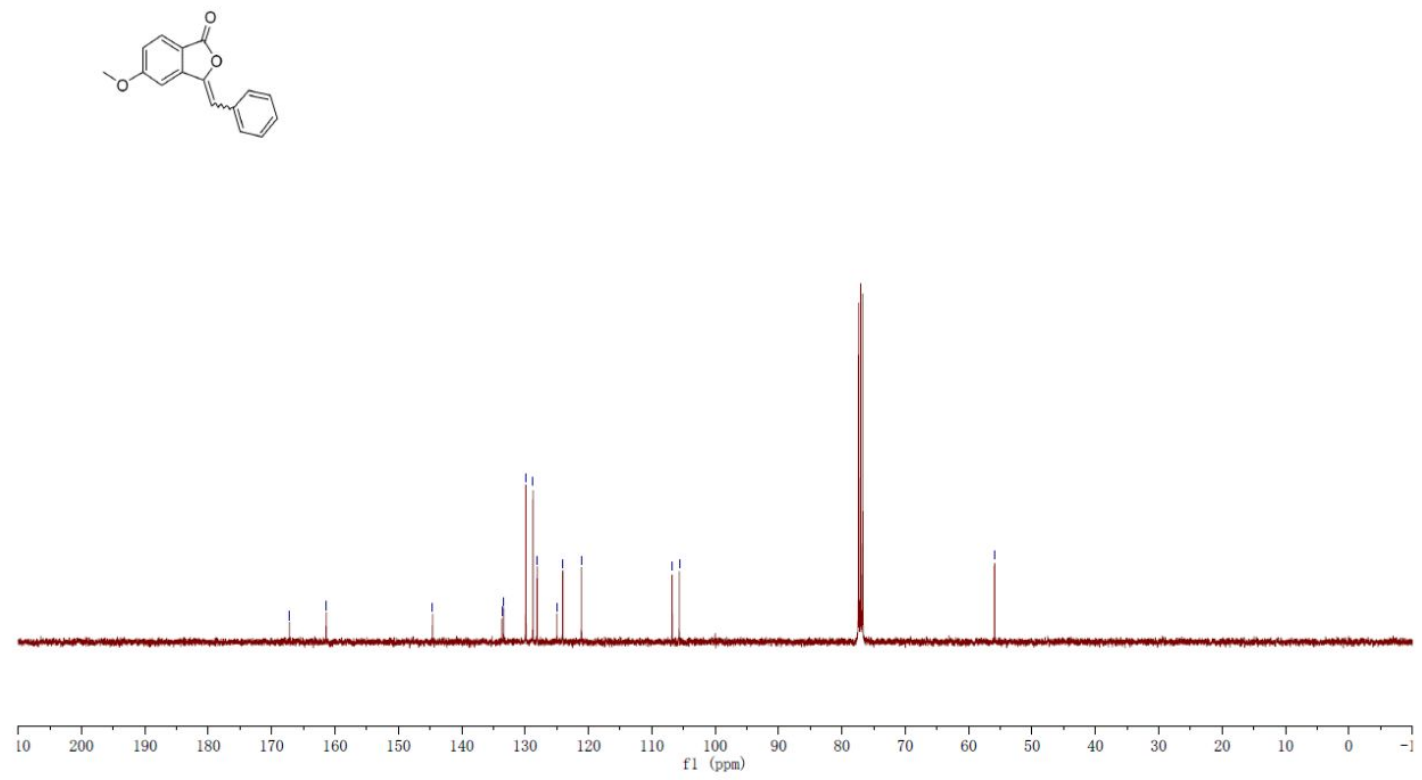
4k ${ }^{1} \mathrm{H}$ NMR (400 MHz, $\mathrm{CDCl}_{3}$ )

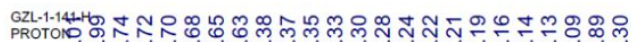

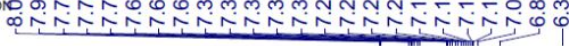
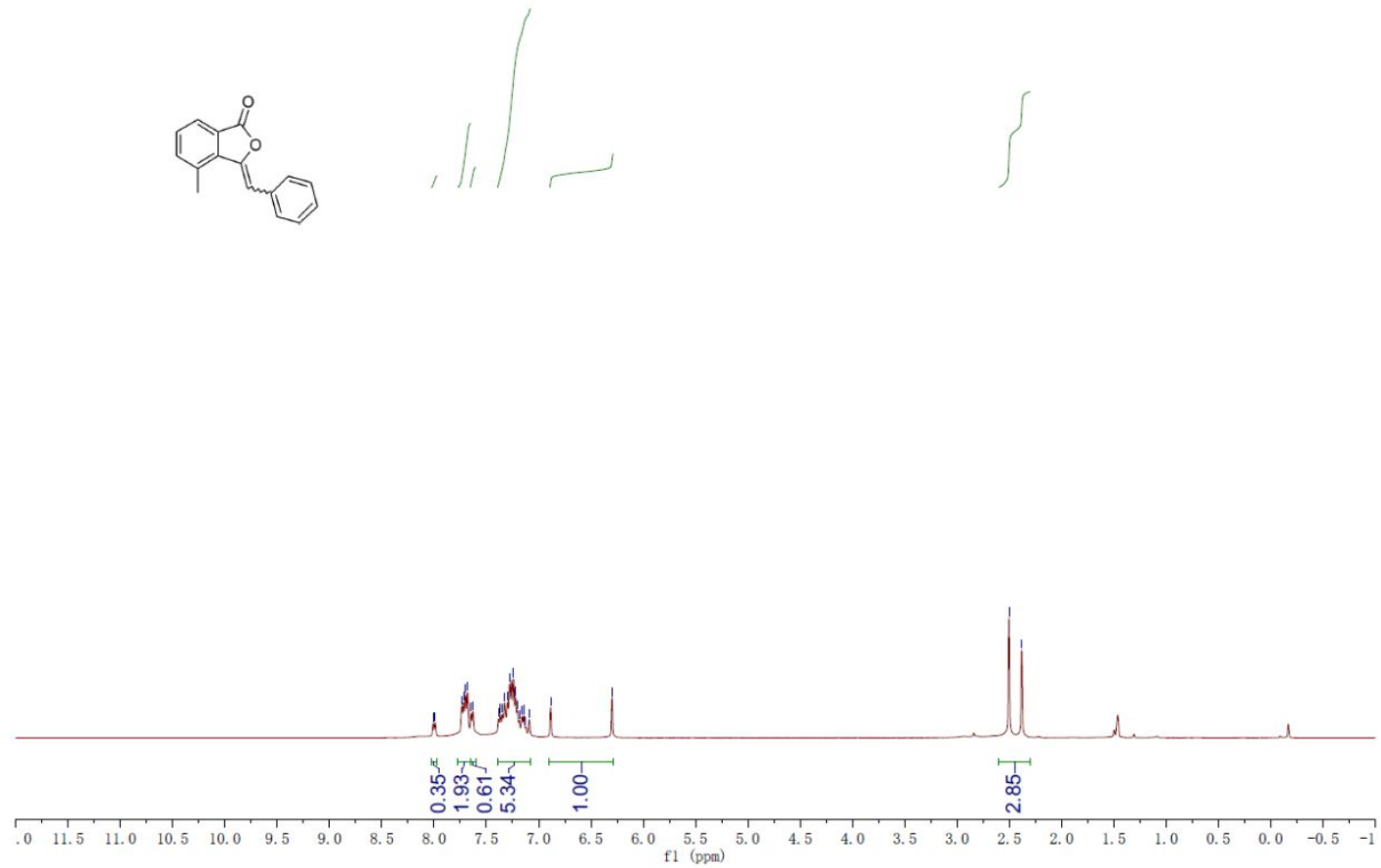

4k ${ }^{13} \mathrm{C}$ NMR $\left(100 \mathrm{MHz}, \mathrm{CDCl}_{3}\right)$

$\underset{\text { CZ1-1 -1 -141-C }}{\text { CICPD }}$

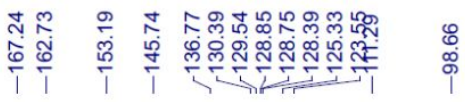

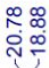
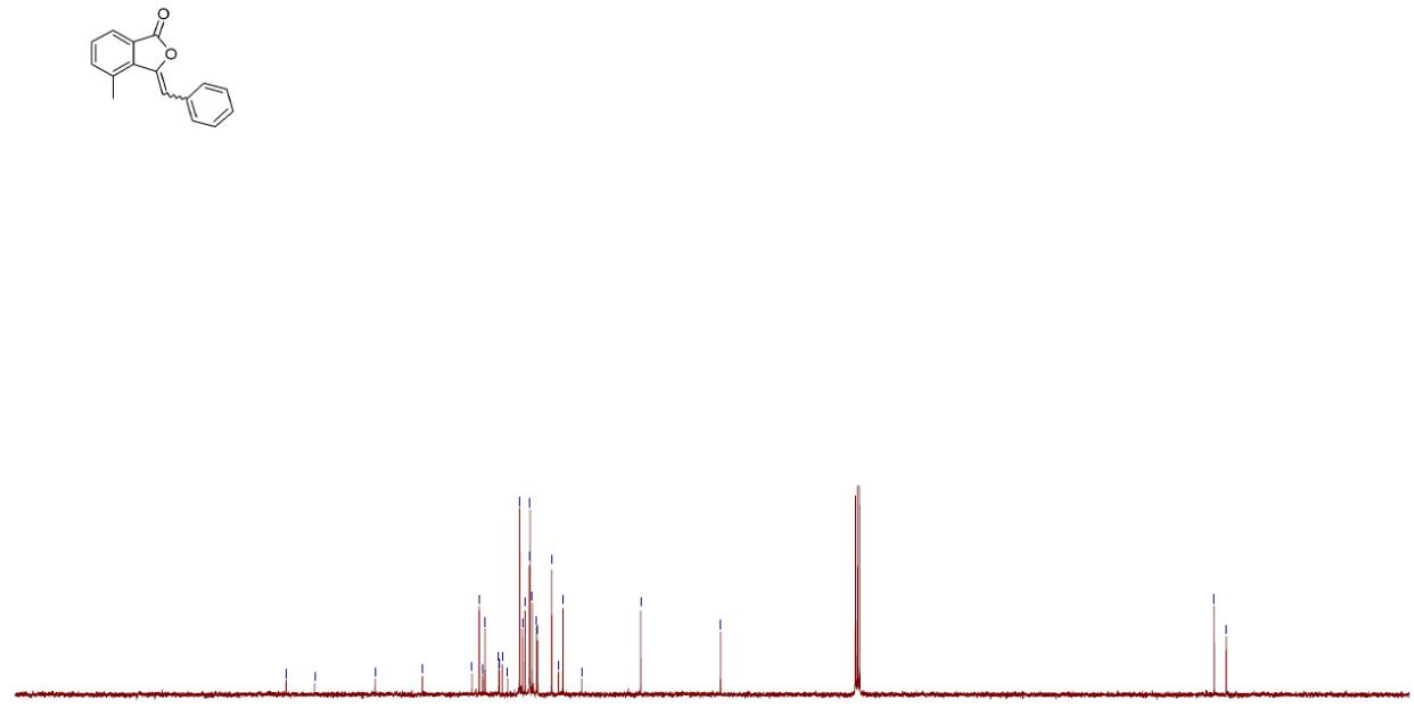

10

$200 \quad 190 \quad 180$

170

${ }_{150}^{1} \quad{ }_{140}^{1}$

120

$110 \quad \underset{f 1}{100}(\mathrm{ppm})$ 
$4{ }^{1} \mathrm{H}$ NMR (400 MHz, $\left.\mathrm{CDCl}_{3}\right)$

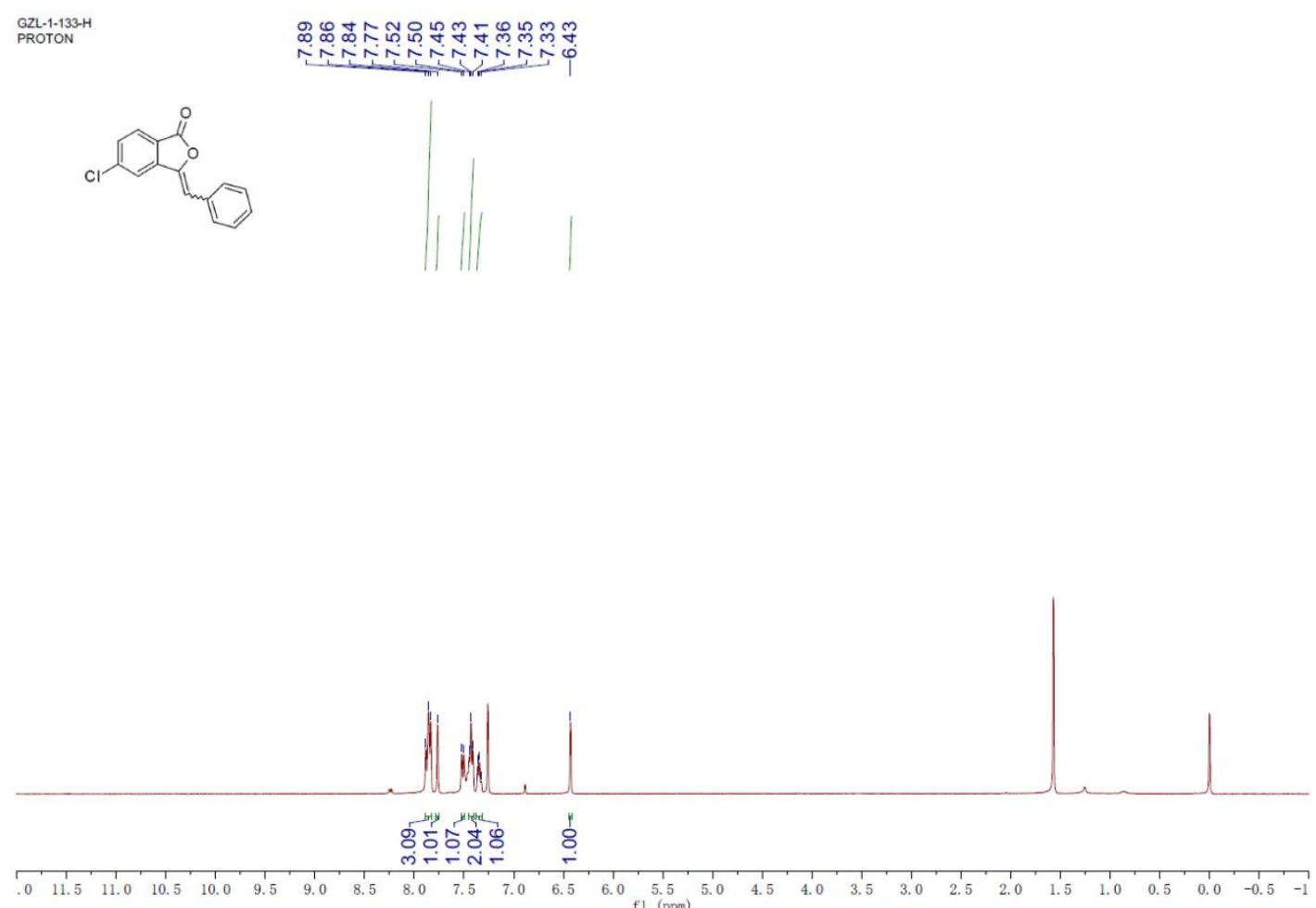

$4 \mathbf{l}^{13} \mathrm{C} \mathrm{NMR}\left(100 \mathrm{MHz}, \mathrm{CDCl}_{3}\right)$

$92-11-132-0$
C13CPD
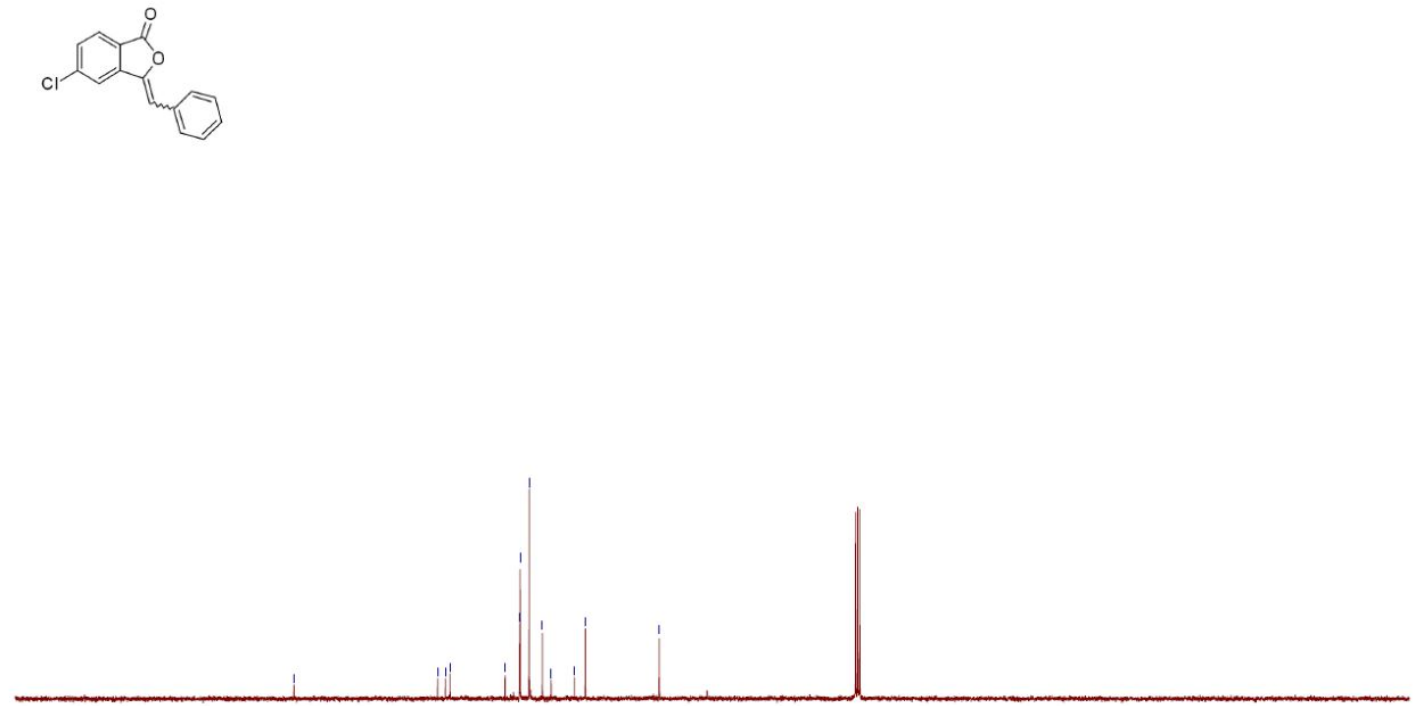

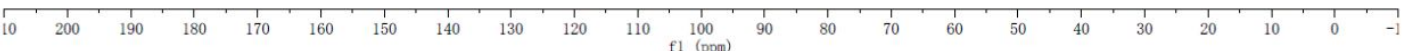


4m ${ }^{1} \mathrm{H}$ NMR (400 MHz, $\mathrm{CDCl}_{3}$ )

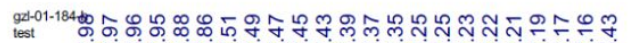

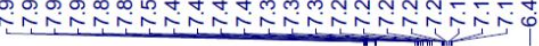
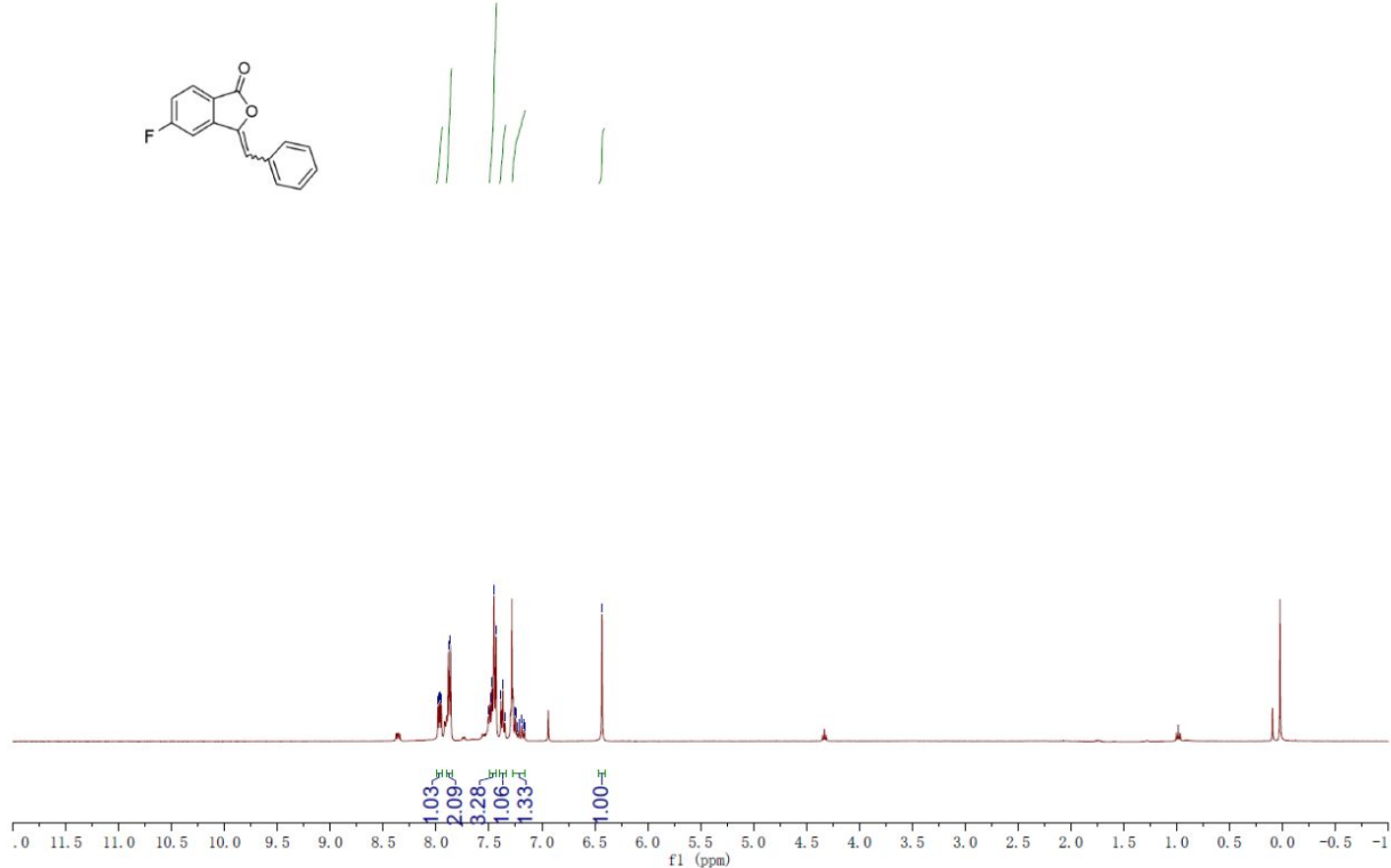

4m ${ }^{13} \mathrm{C}$ NMR $\left(100 \mathrm{MHz}, \mathrm{CDCl}_{3}\right)$

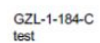

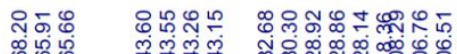

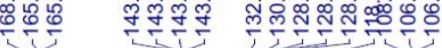
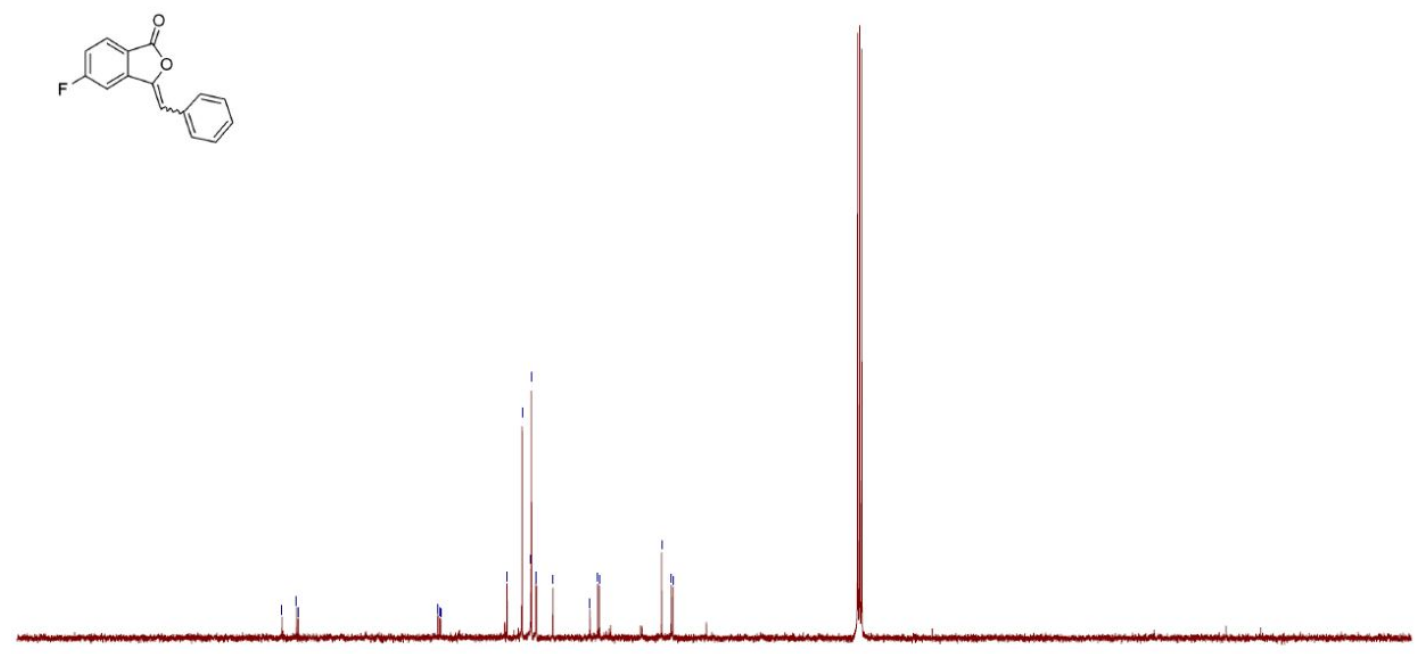

10

170

30

$110 \quad \underset{f 1}{100}(\mathrm{ppm})$ 
7a ${ }^{1} \mathrm{H}$ NMR (400 MHz, $\left.\mathrm{CDCl}_{3}\right)$

GZL-01-74-H
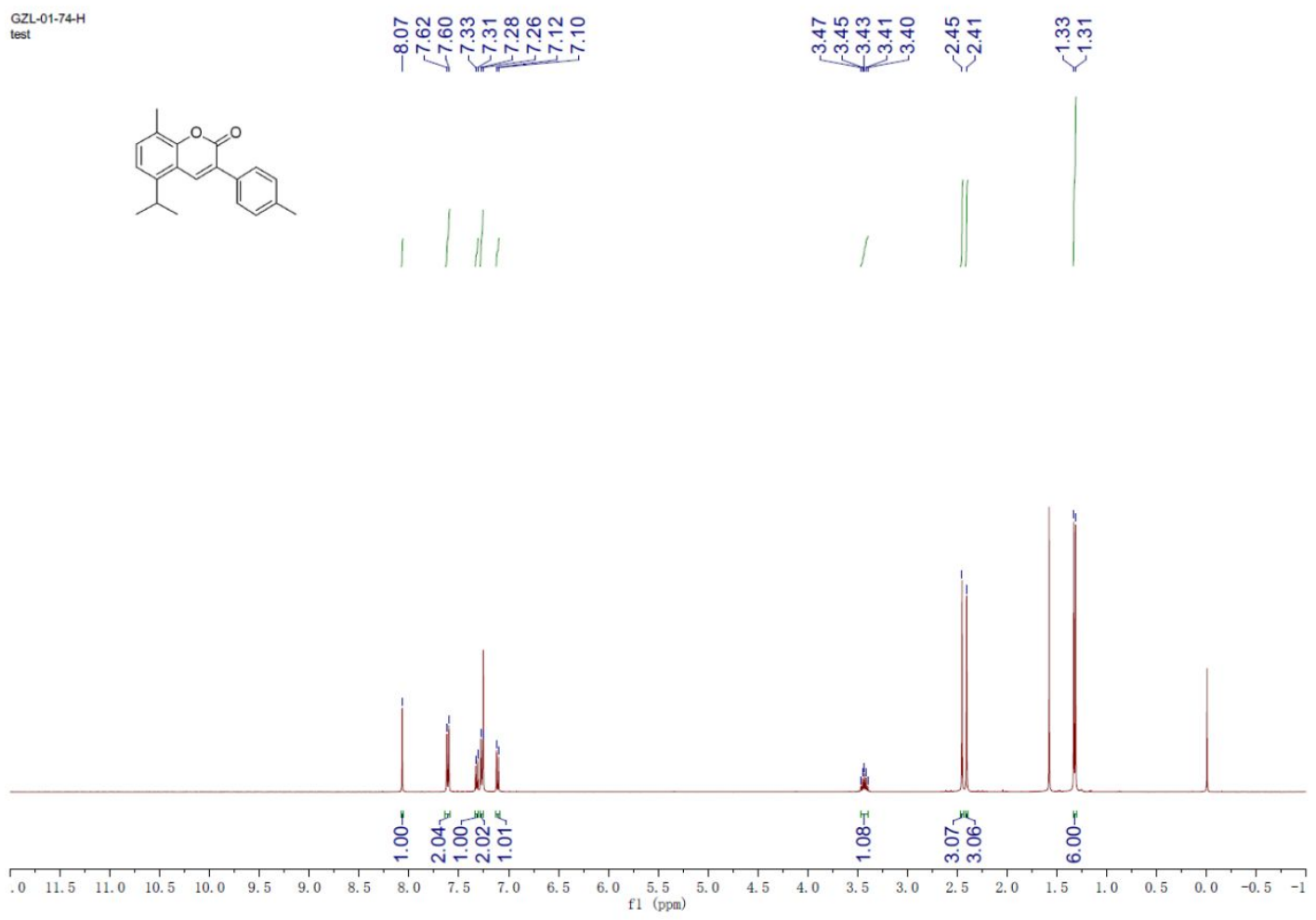

7a ${ }^{13} \mathrm{C}$ NMR $\left(100 \mathrm{MHz}, \mathrm{CDCl}_{3}\right)$

GZL-01-74-C-2
test

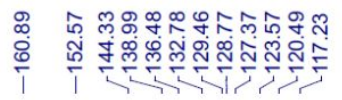

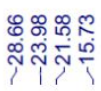
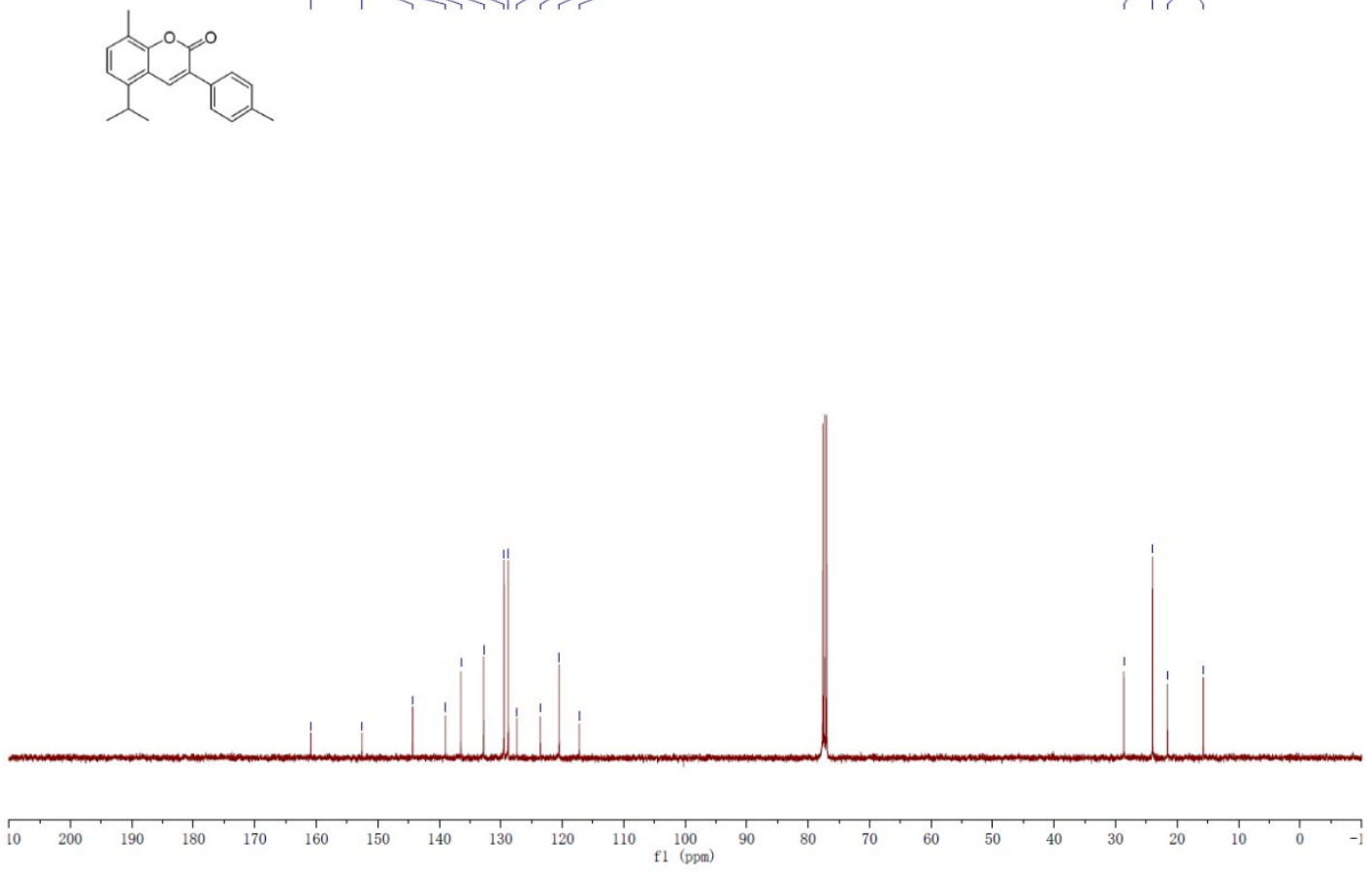

S20 
7b ${ }^{1} \mathrm{H}$ NMR (400 MHz, $\mathrm{CDCl}_{3}$ )

GZL-01-62-H

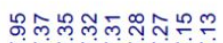

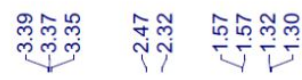

Pyolos

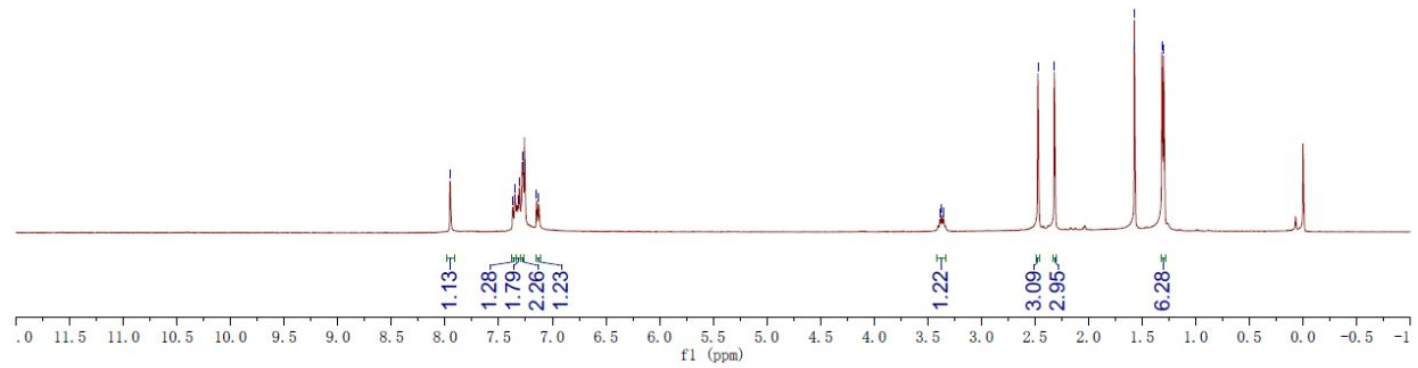

7b ${ }^{13} \mathrm{C}$ NMR $\left(100 \mathrm{MHz}, \mathrm{CDCl}_{3}\right)$

$\underset{\substack{\text { GZL-01-62-C } \\ \text { test }}}{ }$

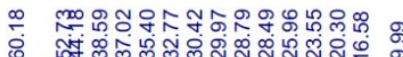

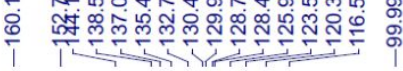

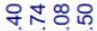

สำกำ

(lone

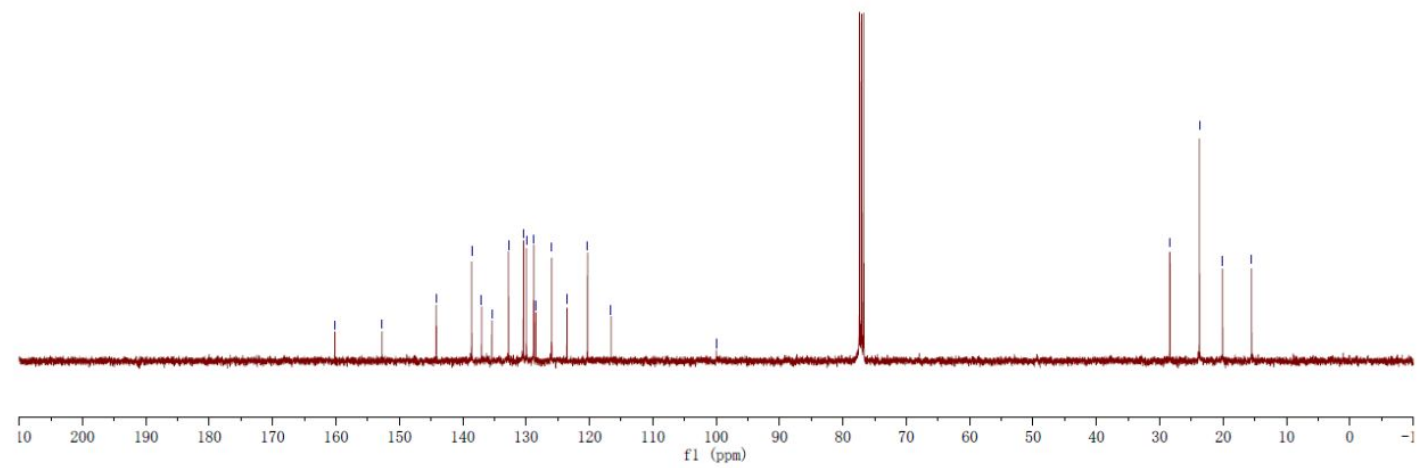


7c ${ }^{1} \mathrm{H}$ NMR $\left(400 \mathrm{MHz}, \mathrm{CDCl}_{3}\right)$

GZL-01-67-H

=

(Yyon
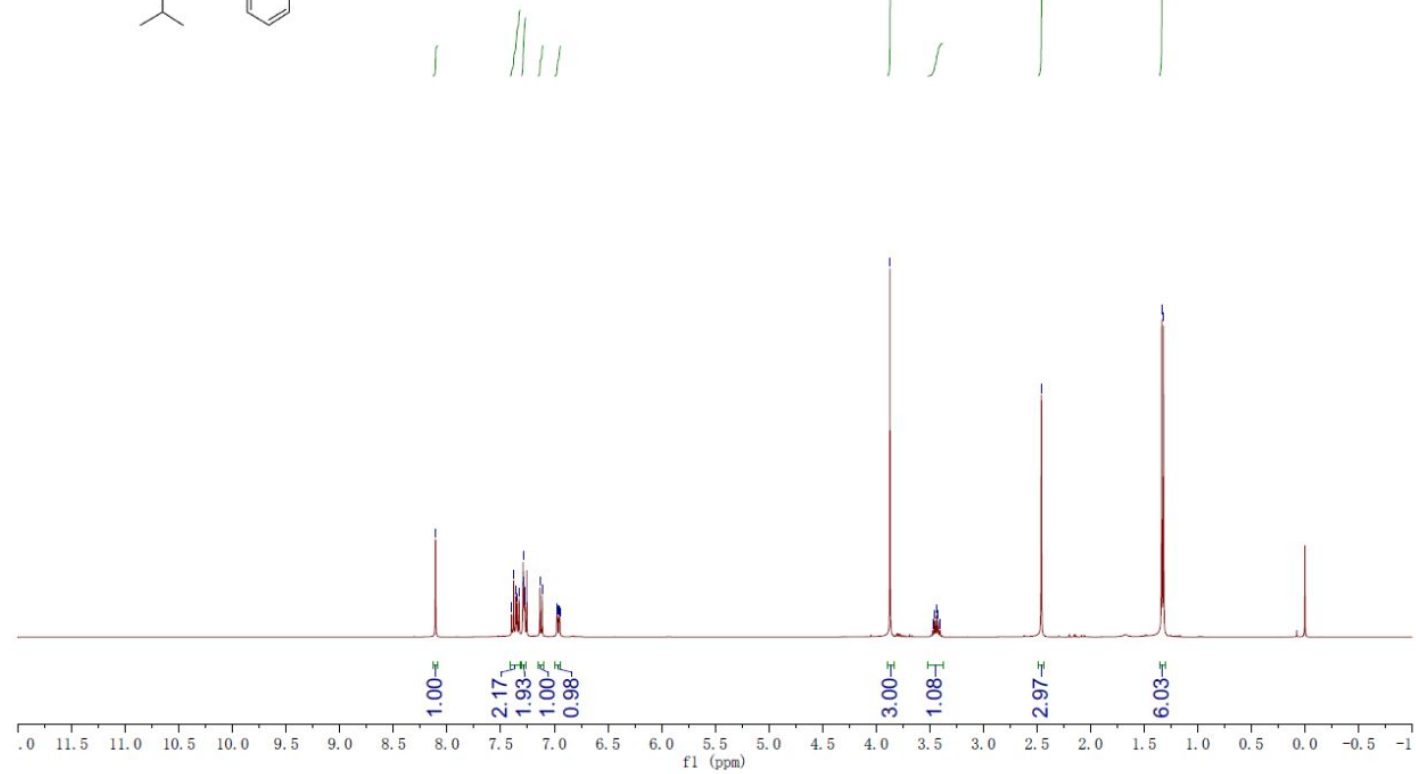

7c ${ }^{13} \mathrm{C}$ NMR $\left(100 \mathrm{MHz}, \mathrm{CDCl}_{3}\right)$

Gz2-01-67-c

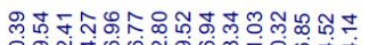

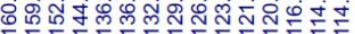

Yon

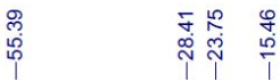

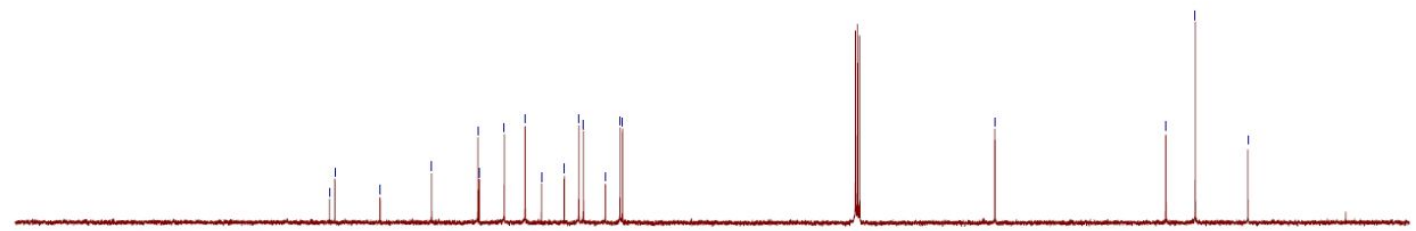

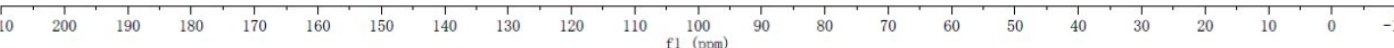


7d ${ }^{1} \mathrm{H}$ NMR (400 MHz, $\mathrm{CDCl}_{3}$ )

GZL-01-64-H
PROTON

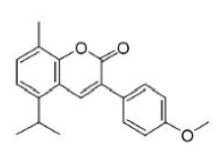

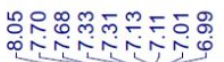

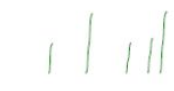

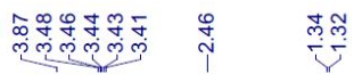
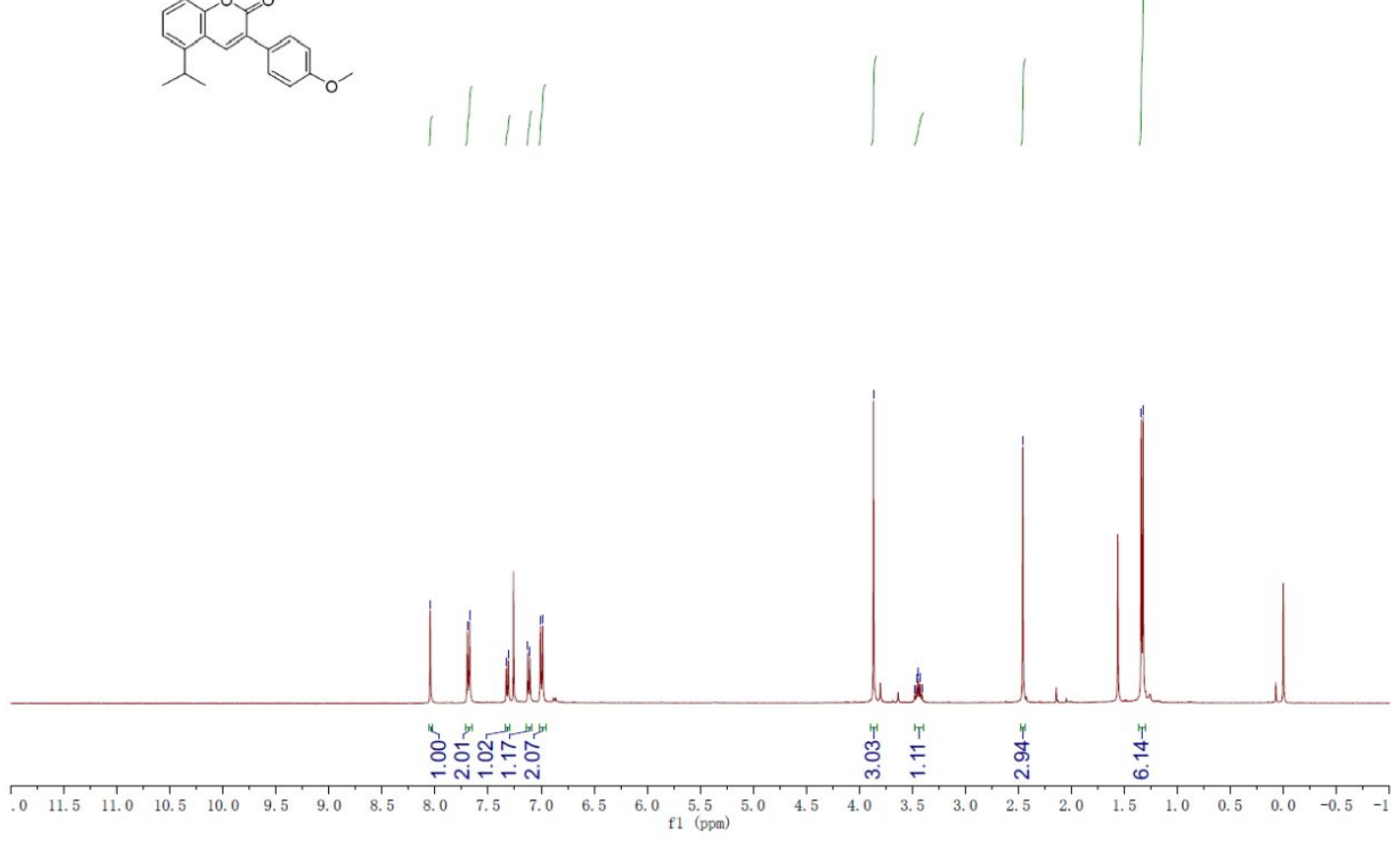

7d $\left.{ }^{13} \mathrm{C} \mathrm{NMR} \mathrm{(100} \mathrm{MHz,} \mathrm{CDCl}_{3}\right)$

GZL-01-64-C

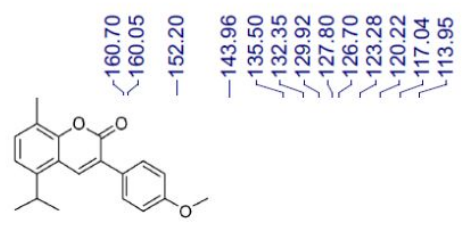

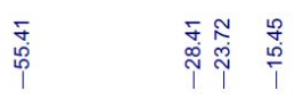
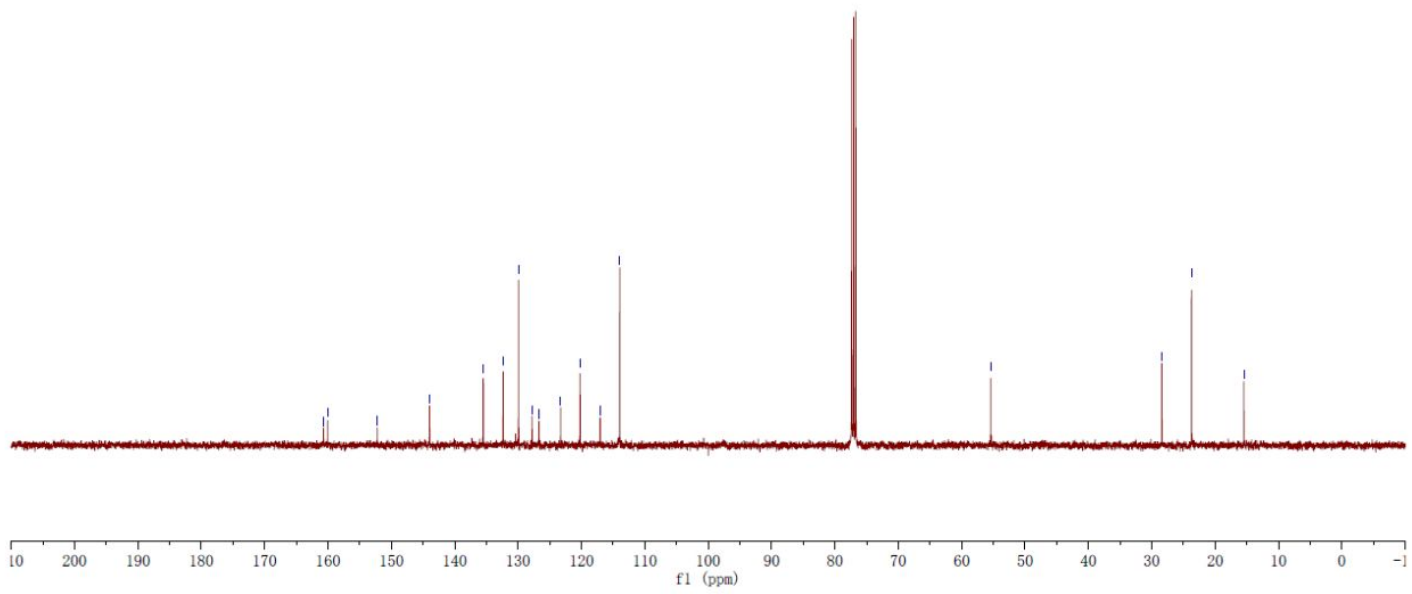

S24 
7e ${ }^{1} \mathrm{H}$ NMR (400 MHz, $\mathrm{CDCl}_{3}$ )

GZL-01-60-H

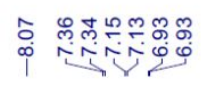

|

氕
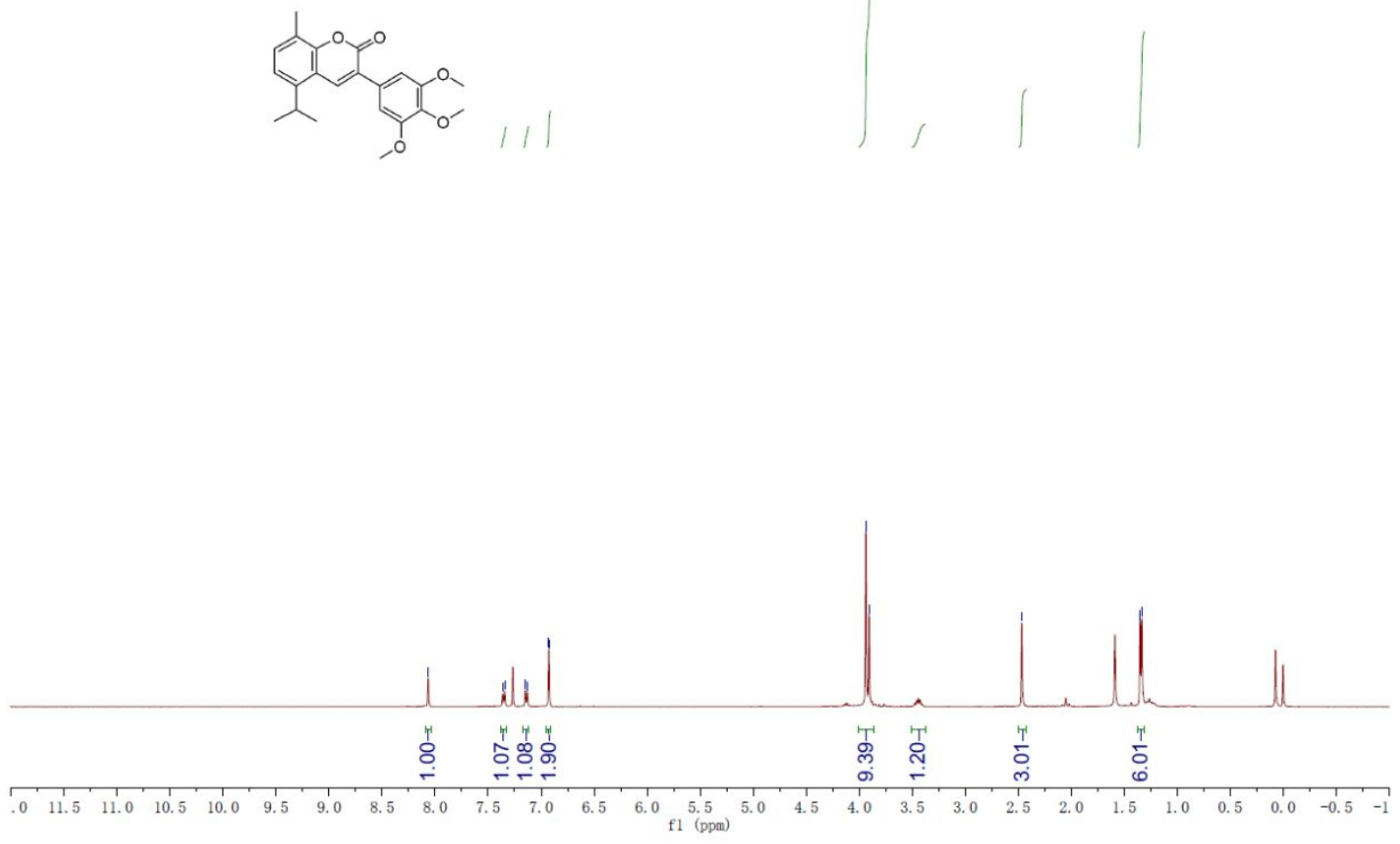

7e ${ }^{13} \mathrm{C}$ NMR (100 MHz, $\left.\mathrm{CDCl}_{3}\right)$
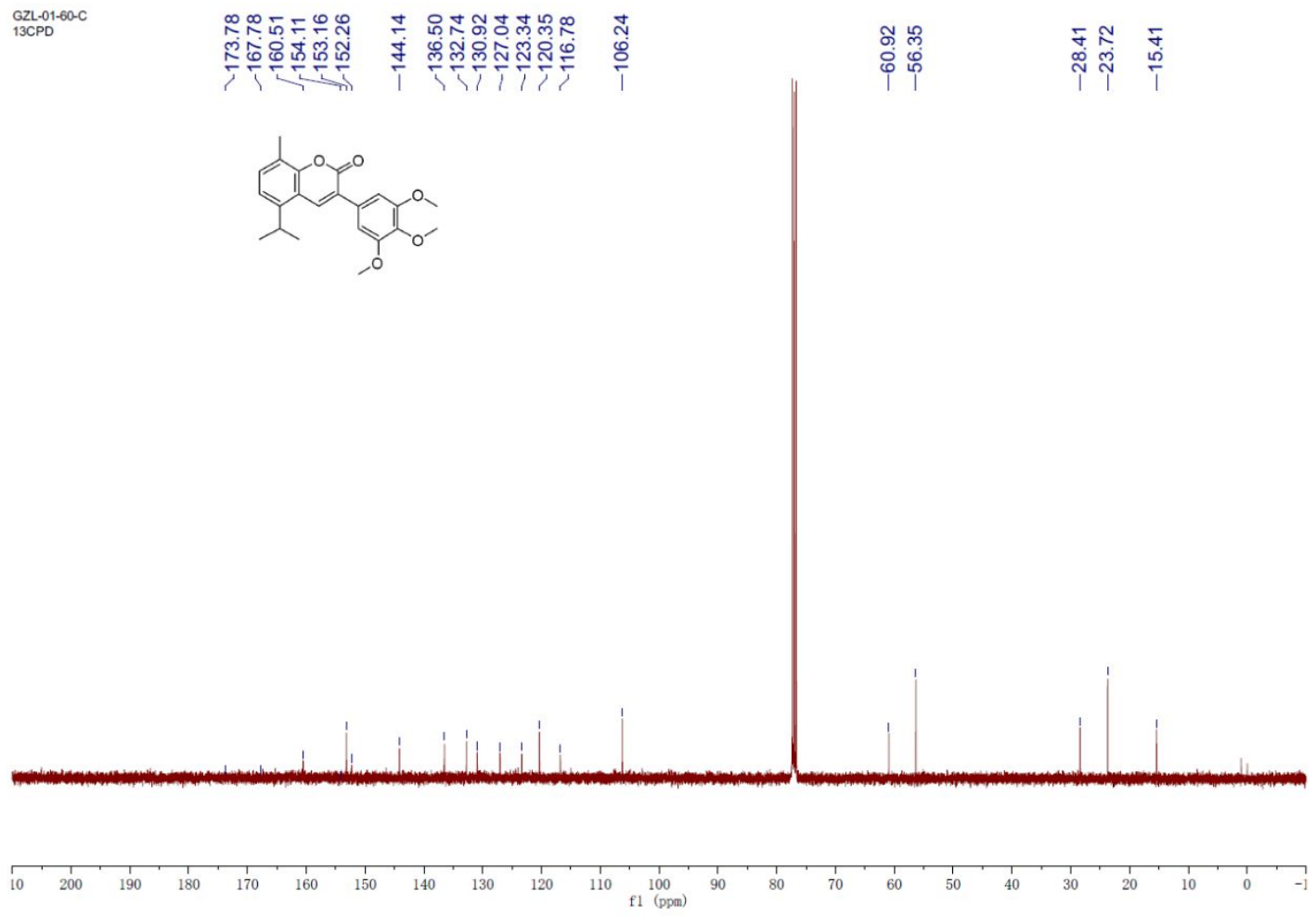

S25 
7f ${ }^{1} \mathrm{H}$ NMR (400 MHz, $\mathrm{CDCl}_{3}$ )

$\underset{\substack{\text { Gest-01-69H } \\ \text { test }}}{2}$

in

Noy
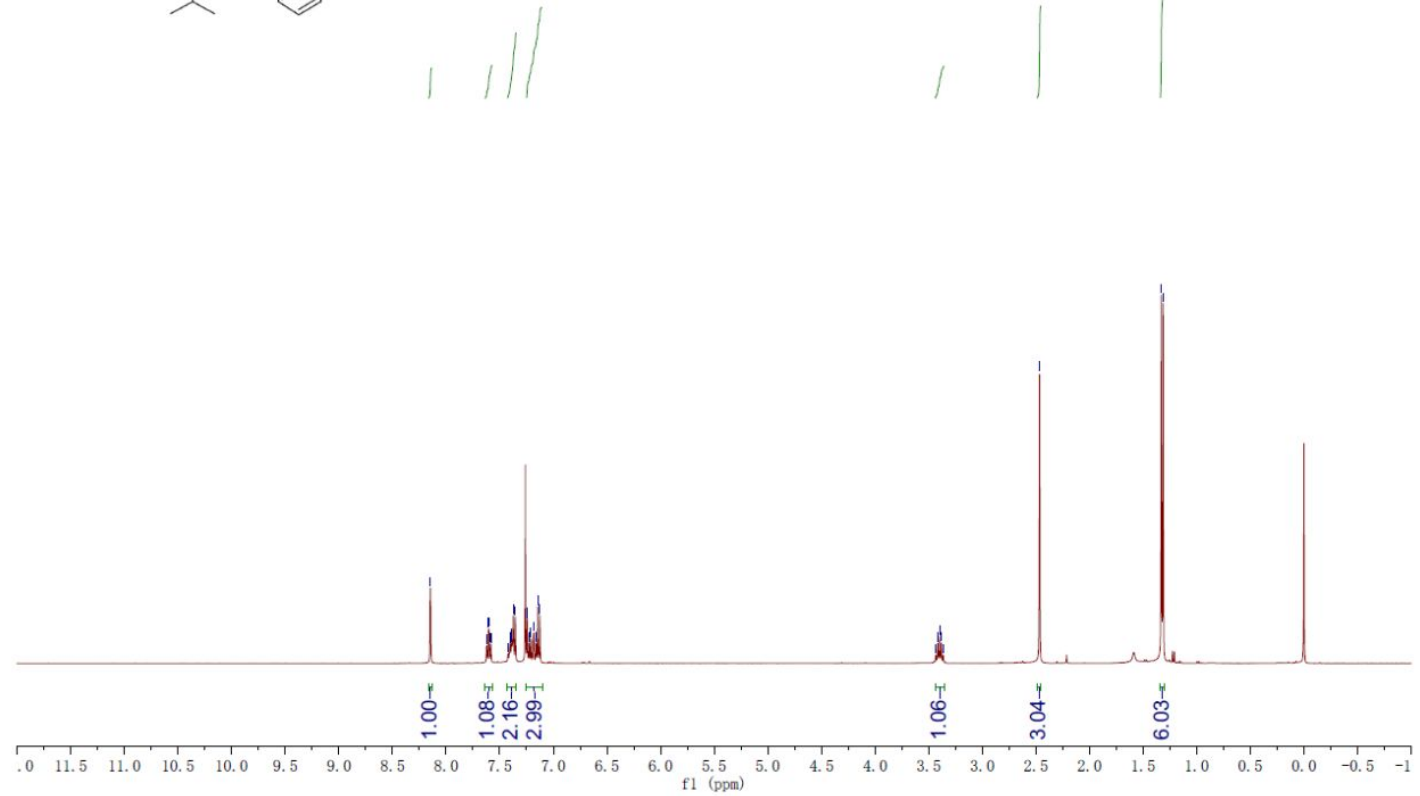

7f ${ }^{13} \mathrm{C} \mathrm{NMR}\left(100 \mathrm{MHz}, \mathrm{CDCl}_{3}\right)$

GZL-01-69.C

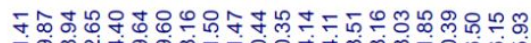

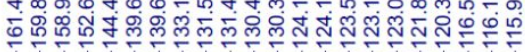

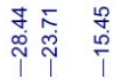

Yon

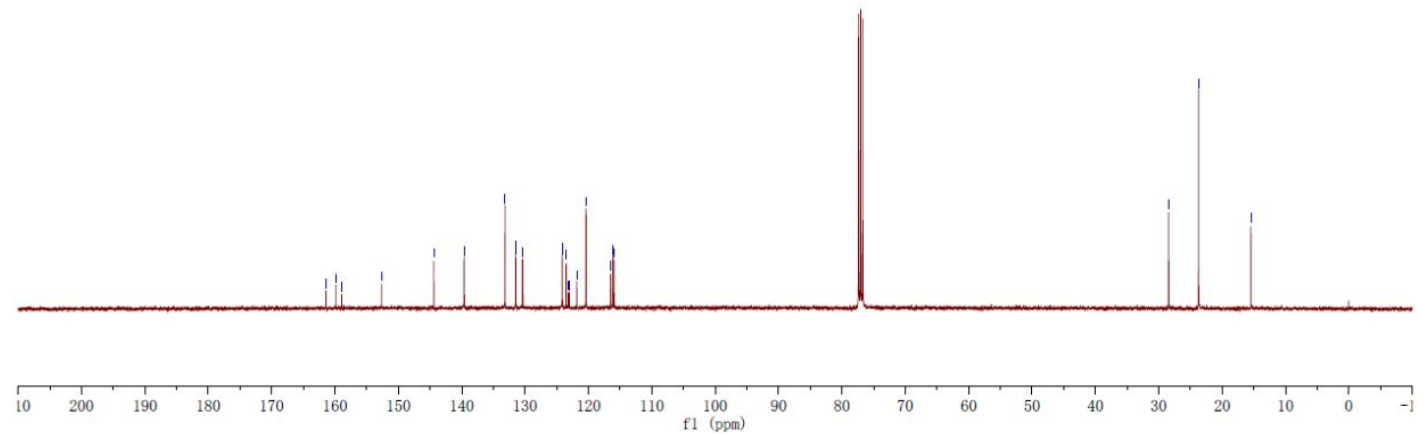


7g ${ }^{1} \mathrm{H}$ NMR (400 MHz, $\mathrm{CDCl}_{3}$ )

$\underset{\text { CZL-01-75 }}{\text { test }}$

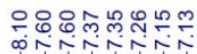

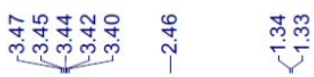

Yor
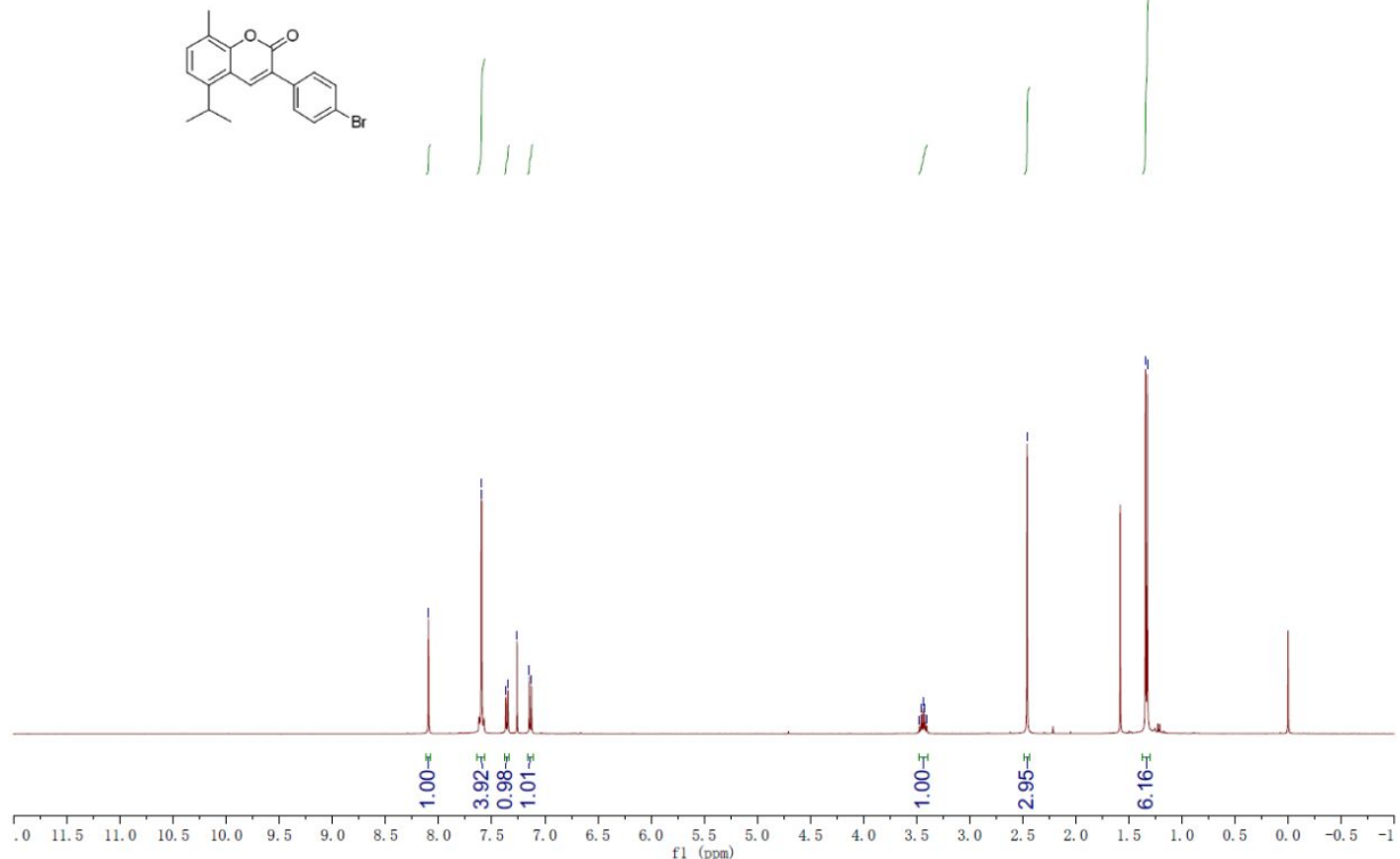

7g ${ }^{13} \mathrm{C} \mathrm{NMR}\left(100 \mathrm{MHz}, \mathrm{CDCl}_{3}\right)$

GZL-01-75-C

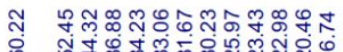

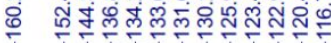

(1)

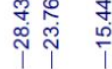

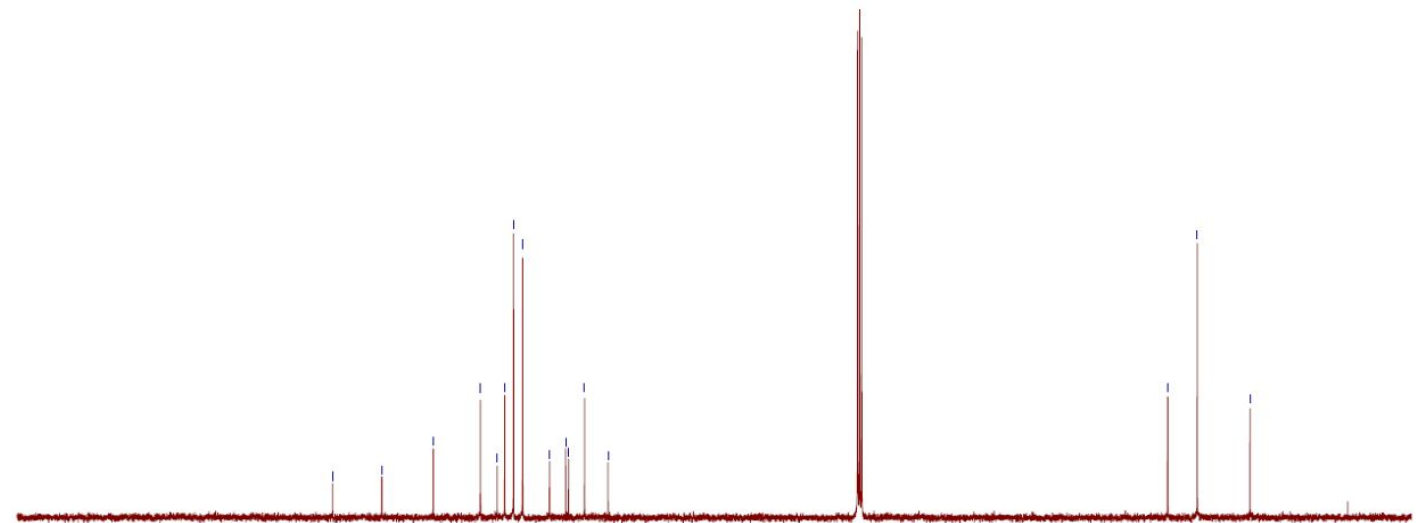


7h ${ }^{1} \mathrm{H}$ NMR (400 MHz, $\mathrm{CDCl}_{3}$ )

GZL-1.0-65-H

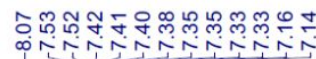

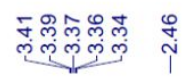

mָ
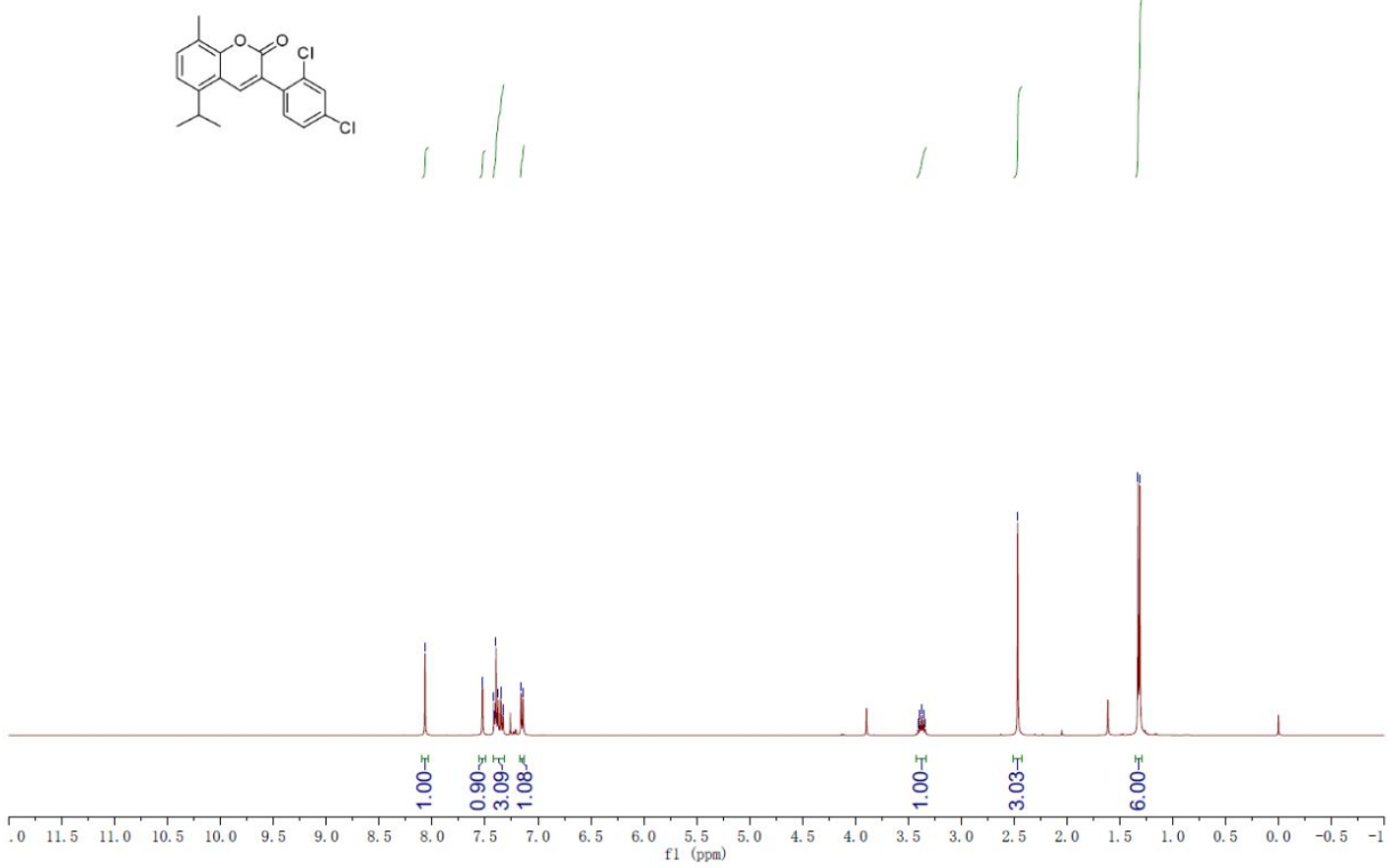

7h ${ }^{13} \mathrm{C}$ NMR (100 MHz, $\left.\mathrm{CDCl}_{3}\right)$

$\underset{\text { C13CPD }}{\text { gz-65-2-c }}$

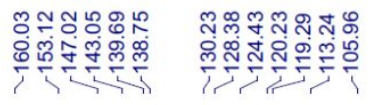

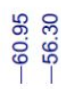
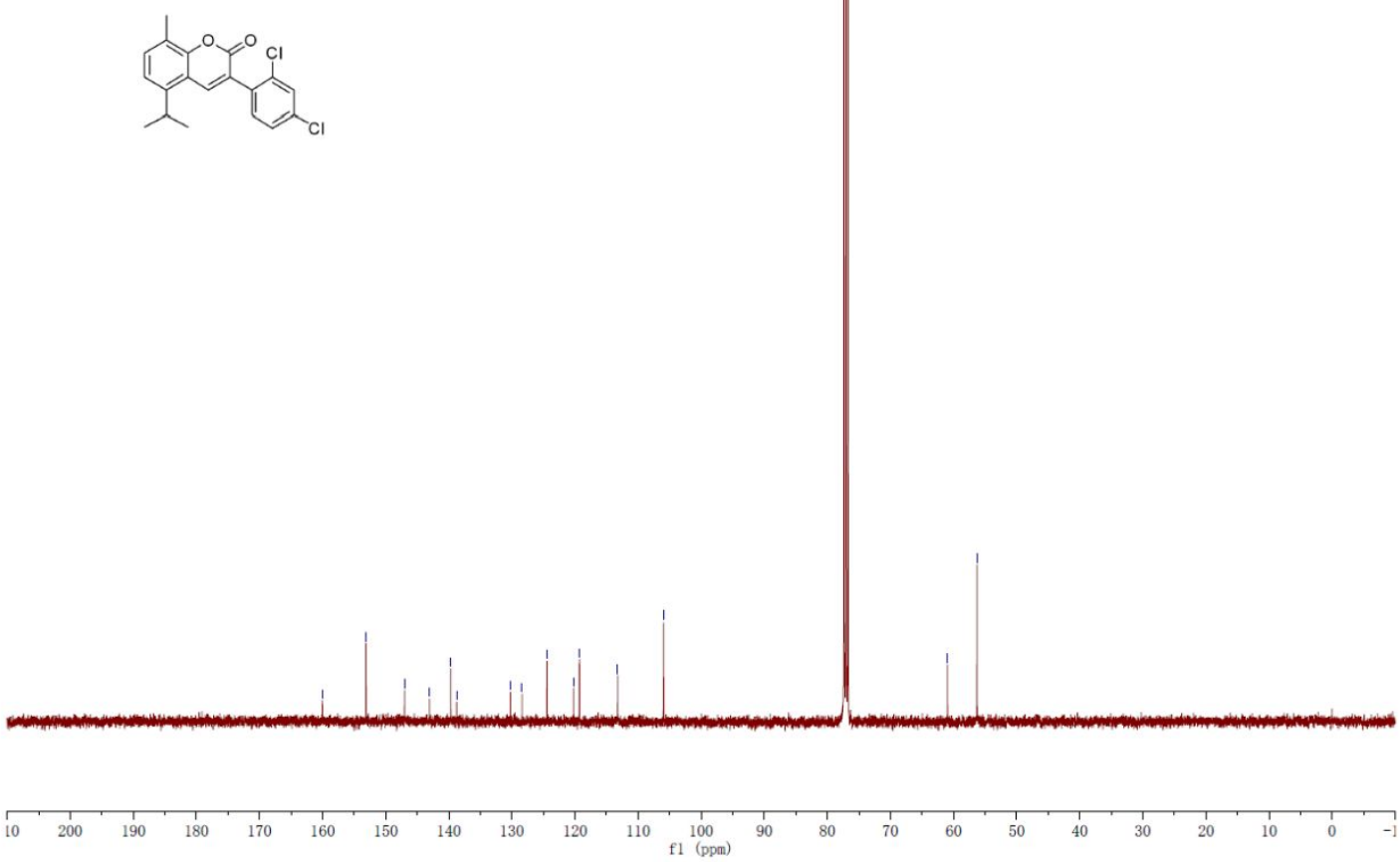

S28 
7i ${ }^{1} \mathrm{H}$ NMR (400 MHz, $\mathrm{CDCl}_{3}$ )

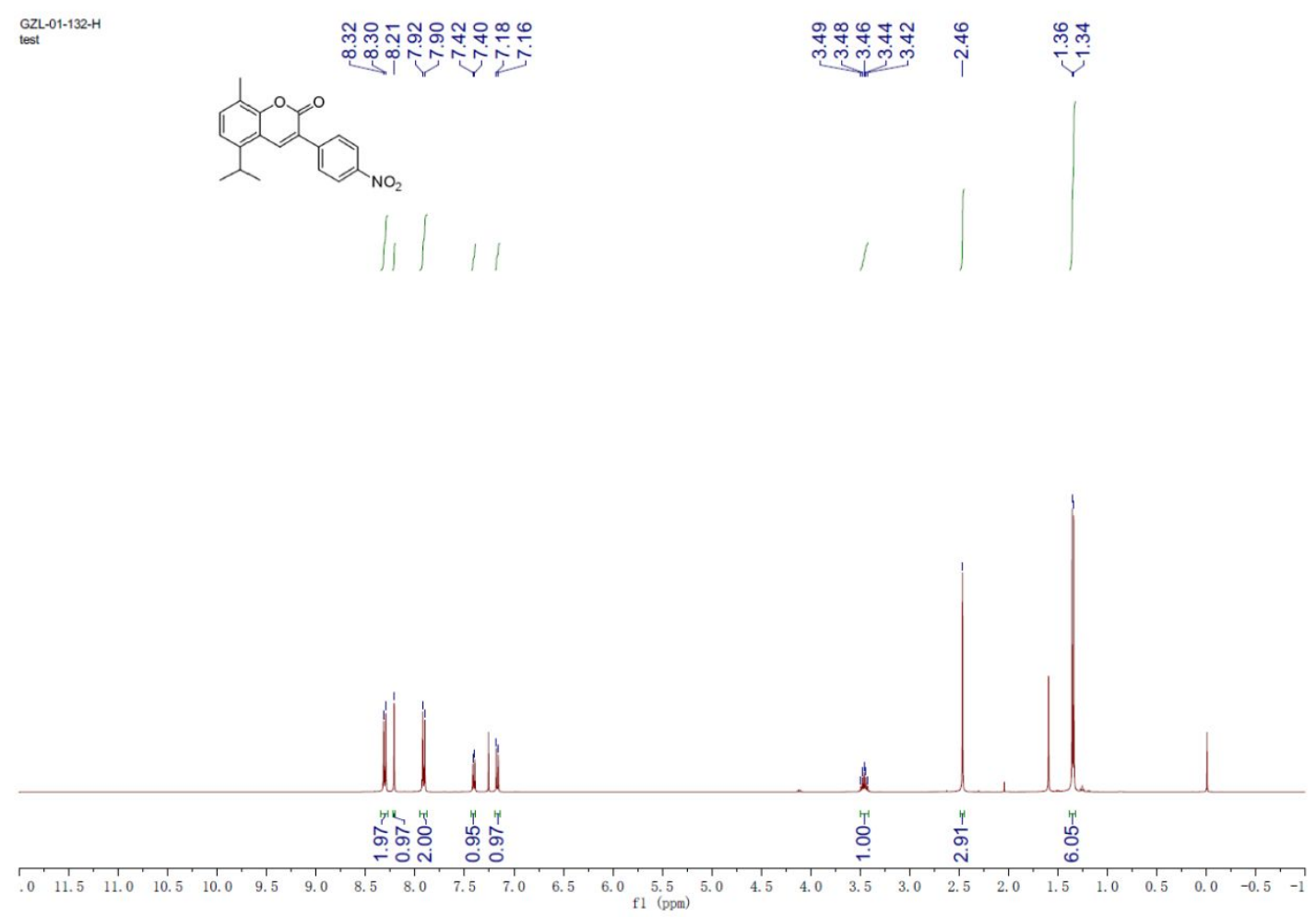

7i ${ }^{13} \mathrm{C}$ NMR (100 MHz, $\left.\mathrm{CDCl}_{3}\right)$

GZL-01-132-C

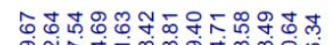

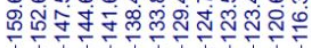

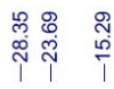

(N)

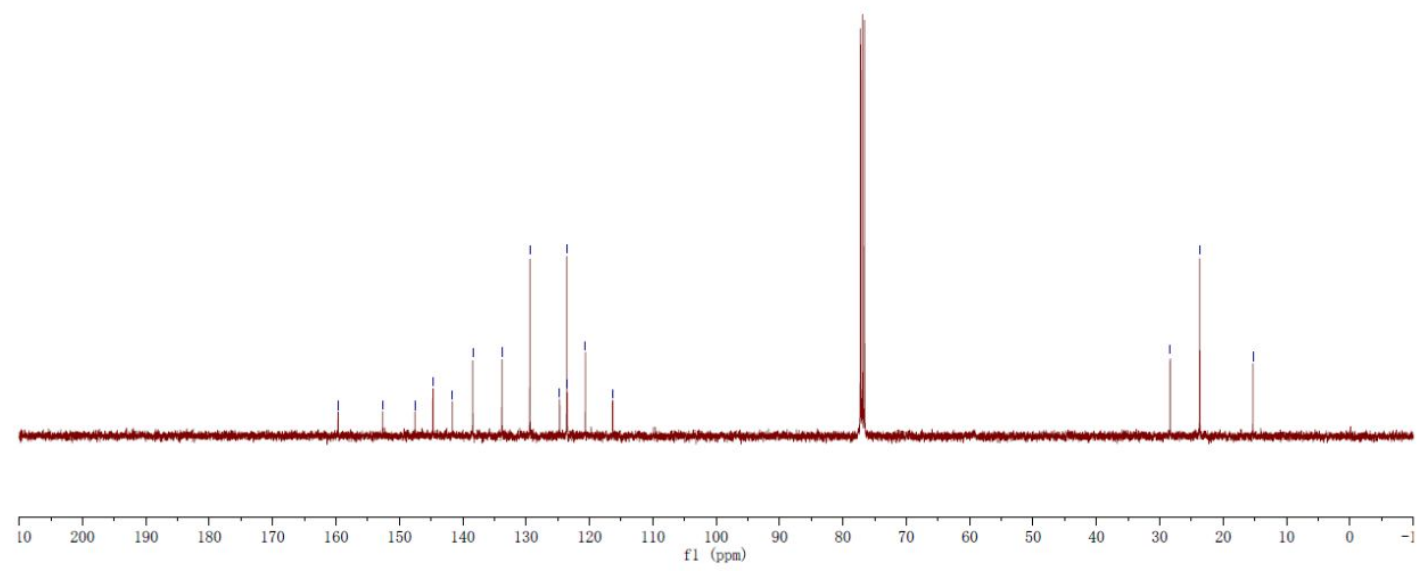


$7 \mathbf{j}^{1} \mathrm{H}$ NMR (400 MHz, $\mathrm{CDCl}_{3}$ )

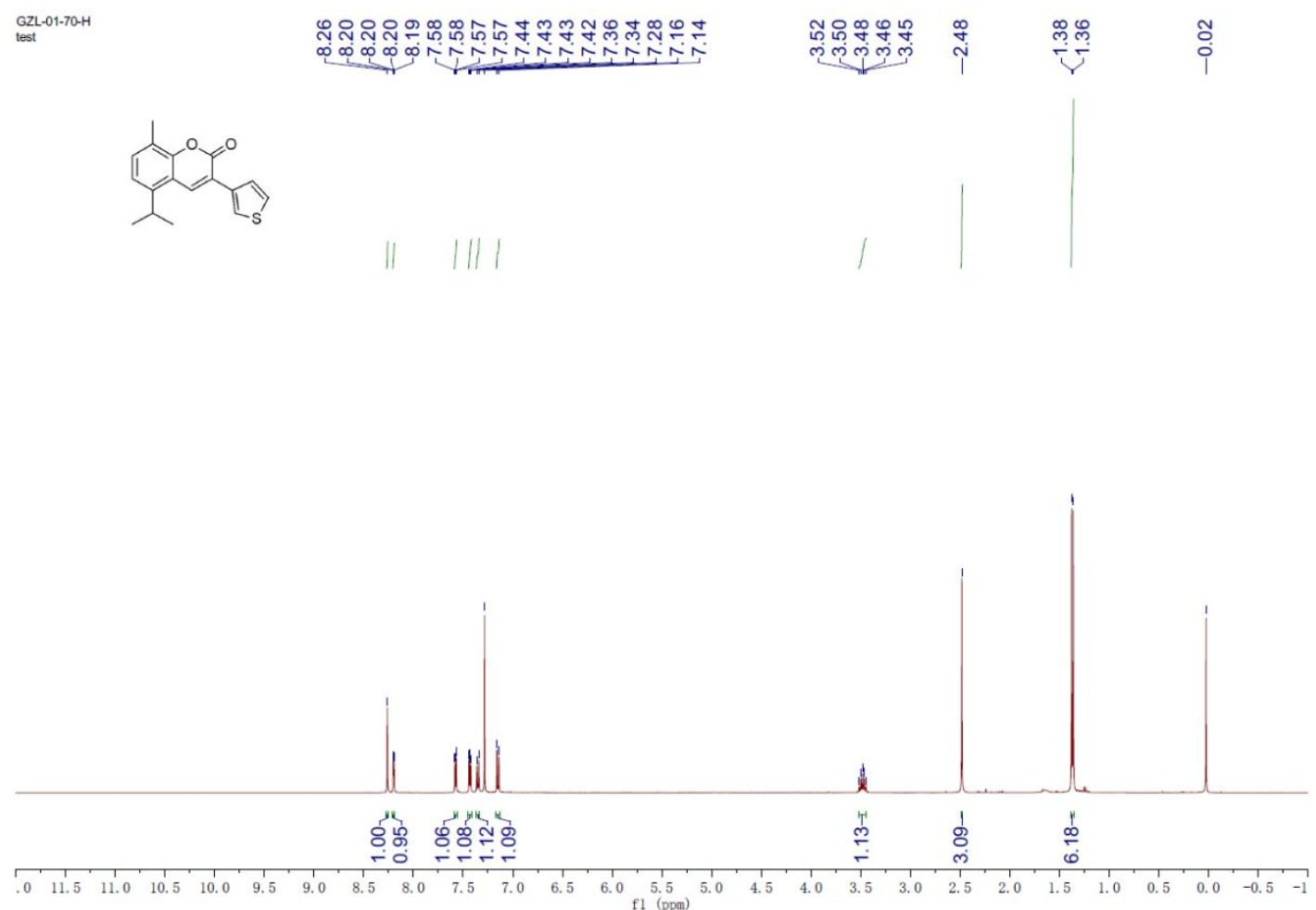

$7 \mathbf{j}{ }^{13} \mathrm{C} \mathrm{NMR}\left(100 \mathrm{MHz}, \mathrm{CDCl}_{3}\right)$
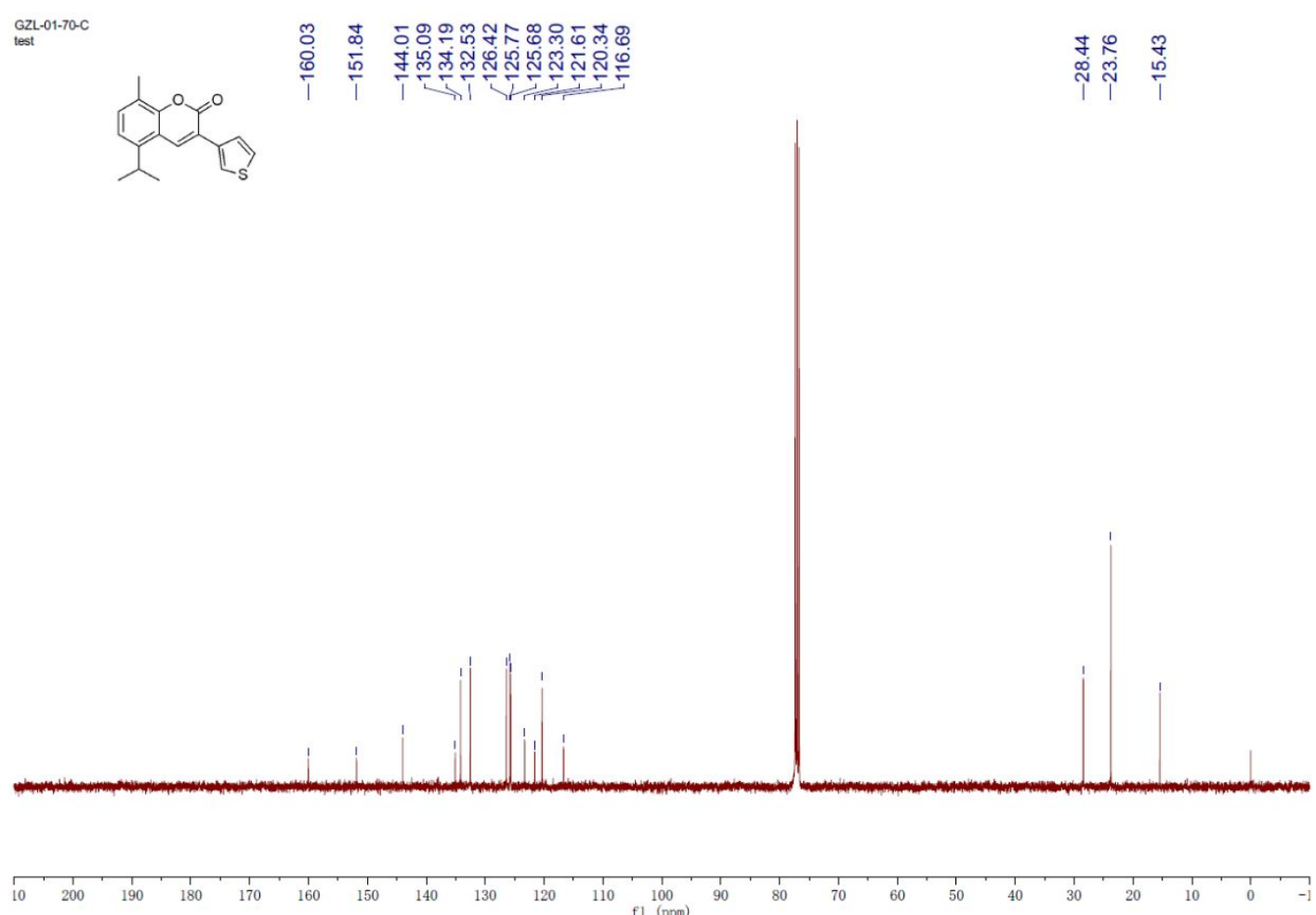
7k ${ }^{1} \mathrm{H}$ NMR (400 MHz, $\mathrm{CDCl}_{3}$ )

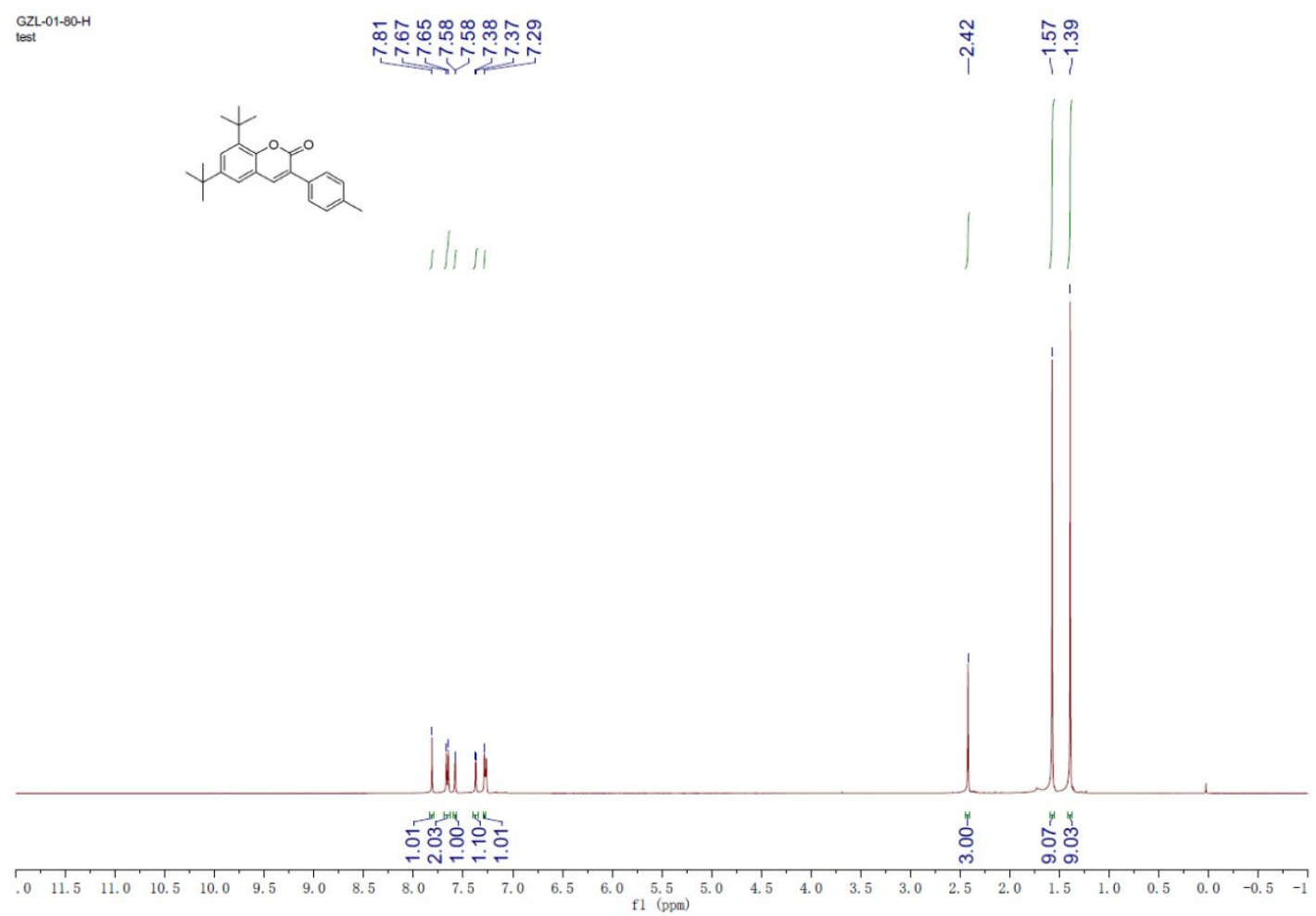

7k ${ }^{13} \mathrm{C}$ NMR (100 MHz, $\left.\mathrm{CDCl}_{3}\right)$

GZL-01-80-C
test

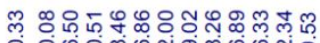

ดे

는

ธळ్యల్ల

फूलำ
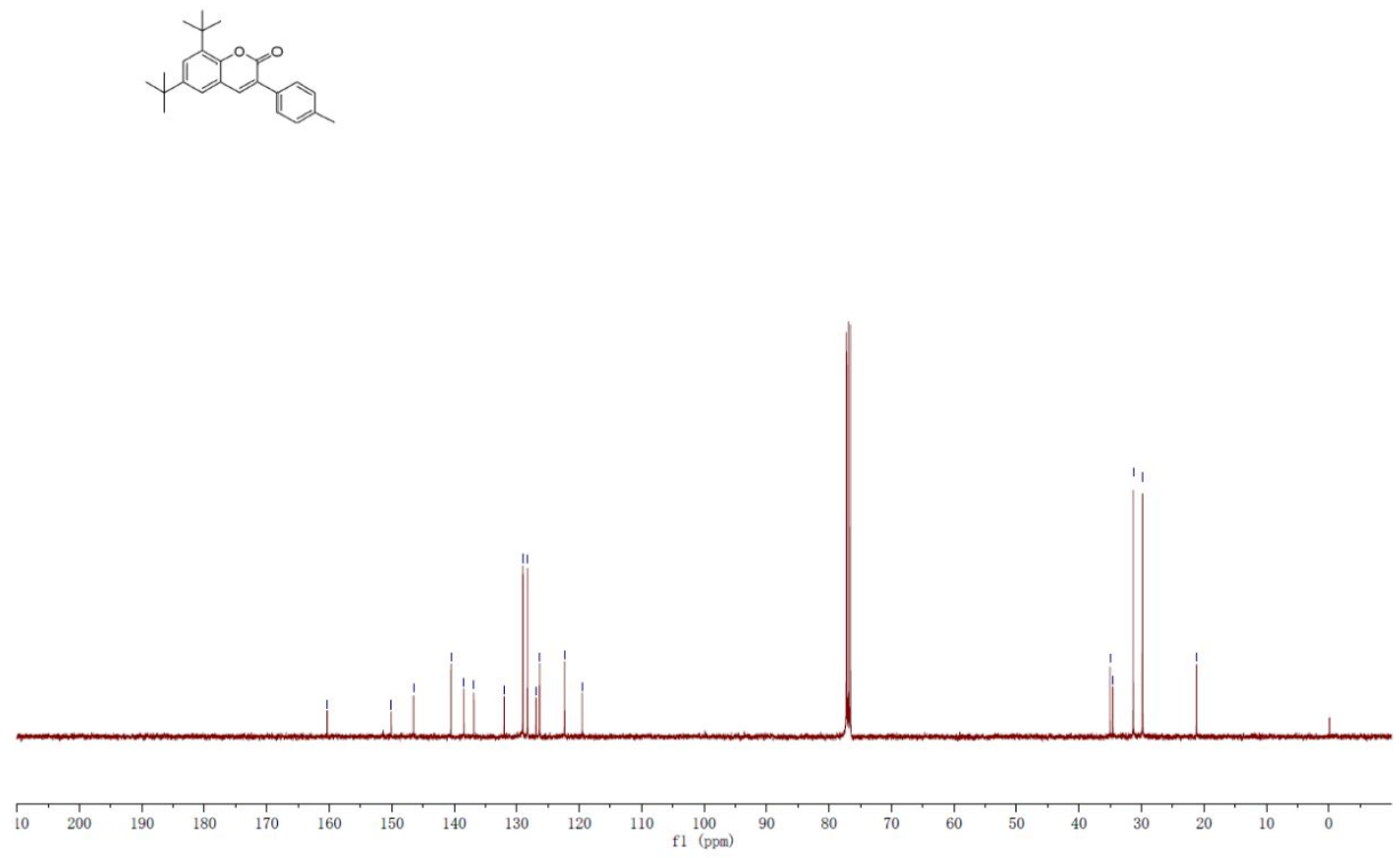
7l ${ }^{1} \mathrm{H}$ NMR (400 MHz, $\mathrm{CDCl}_{3}$ )

GZL-01-79
PROTTN
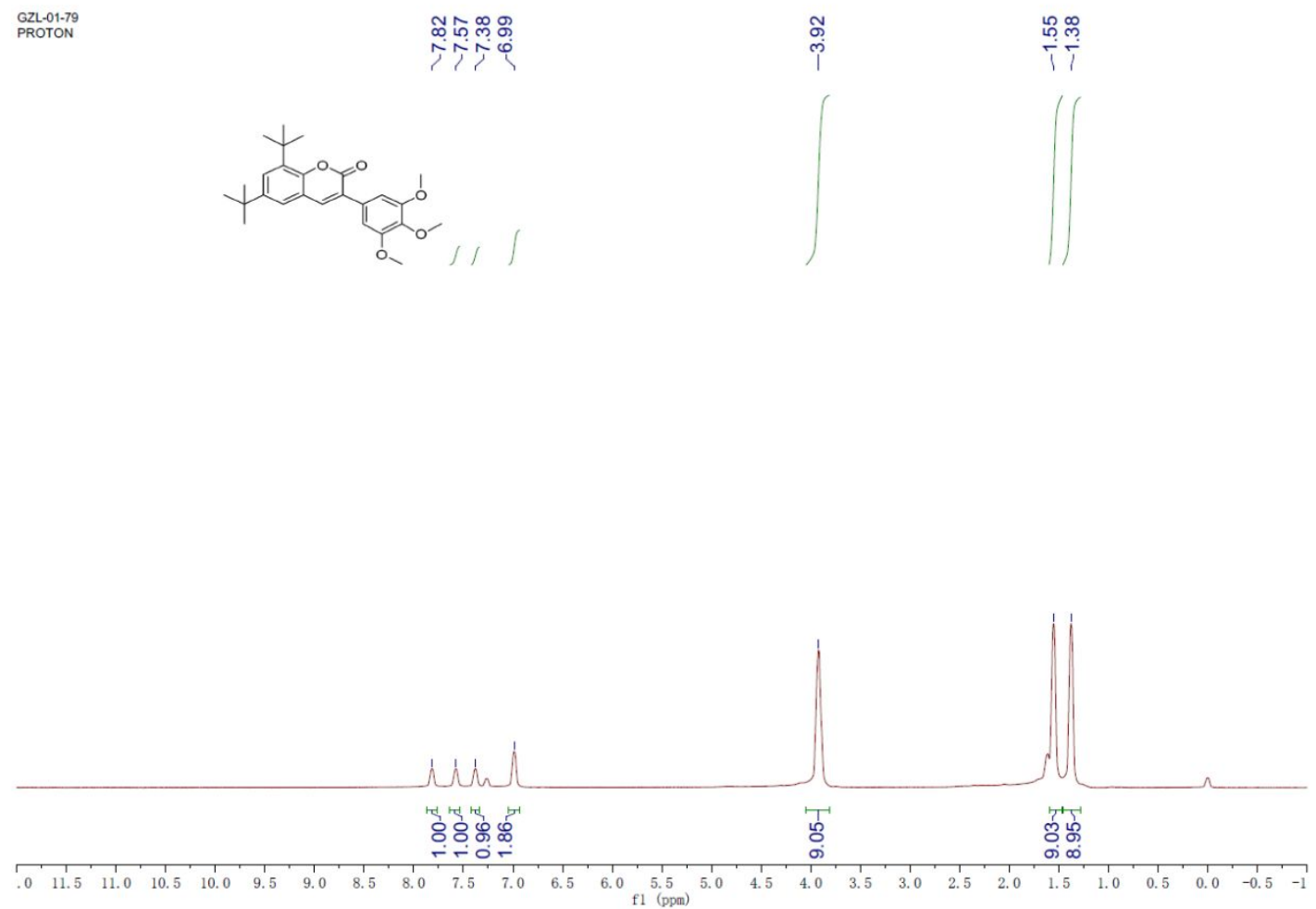

7l ${ }^{13} \mathrm{C}$ NMR (100 MHz, $\left.\mathrm{CDCl}_{3}\right)$

\begin{tabular}{|c|c|c|c|c|}
\hline $\begin{array}{l}\text { C2LL-01-C.-79 } \\
\text { C13CPD }\end{array}$ & 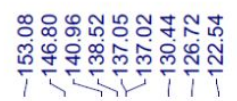 & 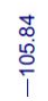 & 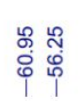 & 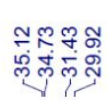 \\
\hline
\end{tabular}

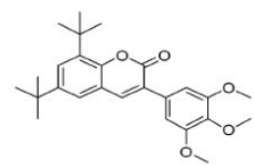

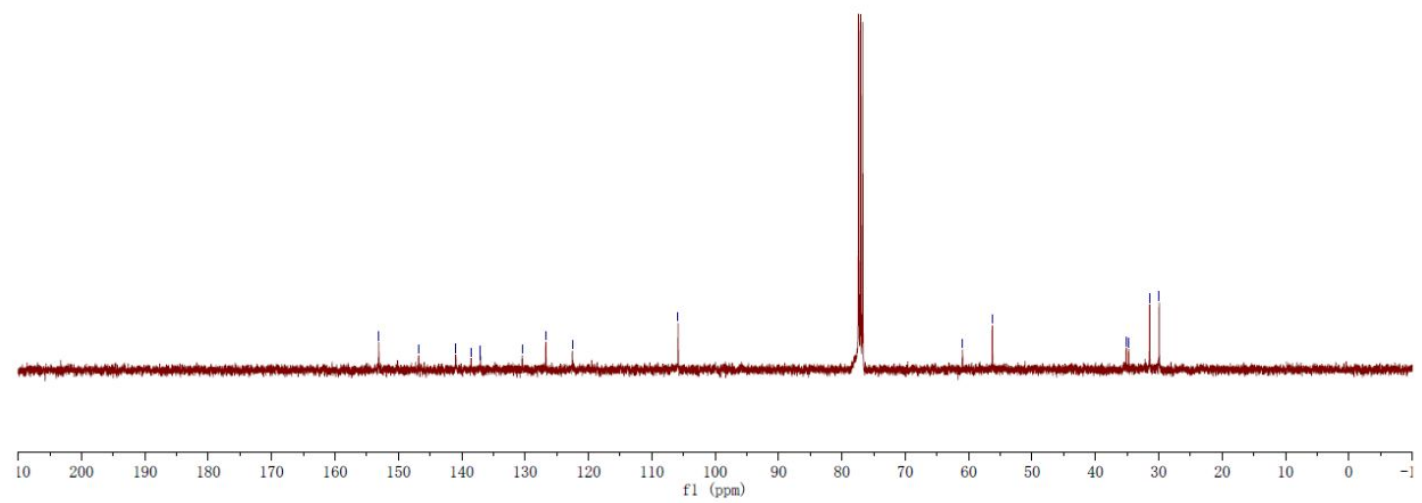


7m ${ }^{1} \mathrm{H}$ NMR (400 MHz, $\mathrm{CDCl}_{3}$ )

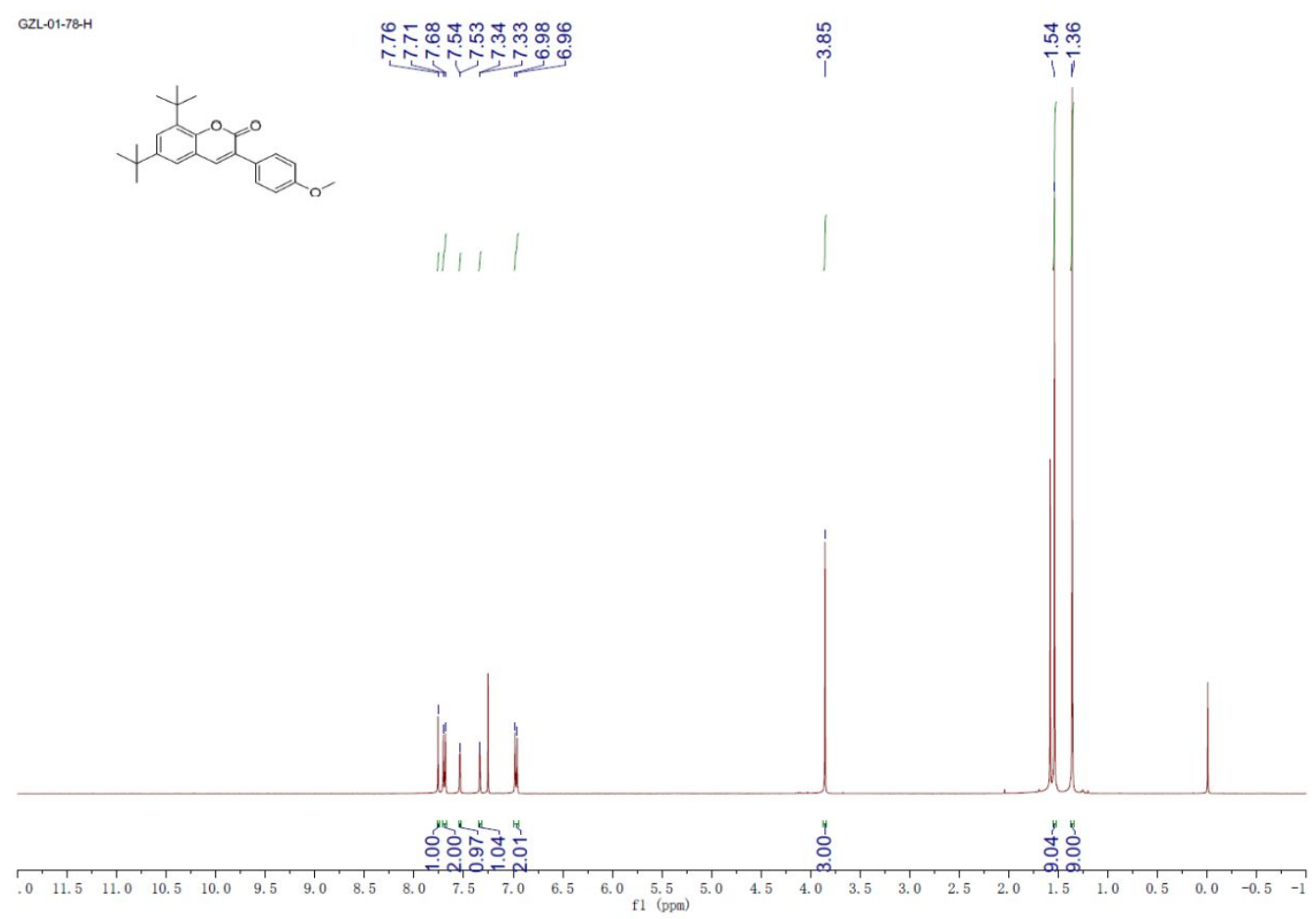

7m ${ }^{13} \mathrm{C}$ NMR (100 MHz, $\left.\mathrm{CDCl}_{3}\right)$

GZL-01-78-C
test

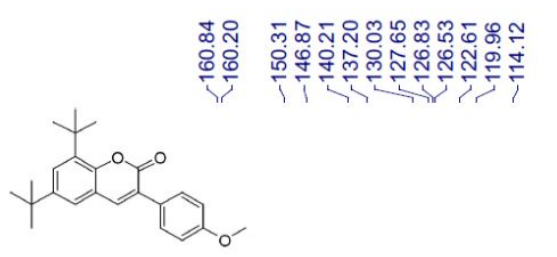

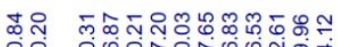

인

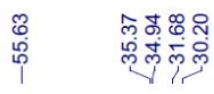

$10 \quad 200$

${ }_{190}^{1} \quad{ }_{180}^{1} \quad 170 \quad 160$

${ }_{150}^{1} 140$

120

$110 \underset{\mathrm{fl}}{100}(\mathrm{ppm})$ 
7n ${ }^{1} \mathrm{H}$ NMR (400 MHz, $\left.\mathrm{CDCl}_{3}\right)$

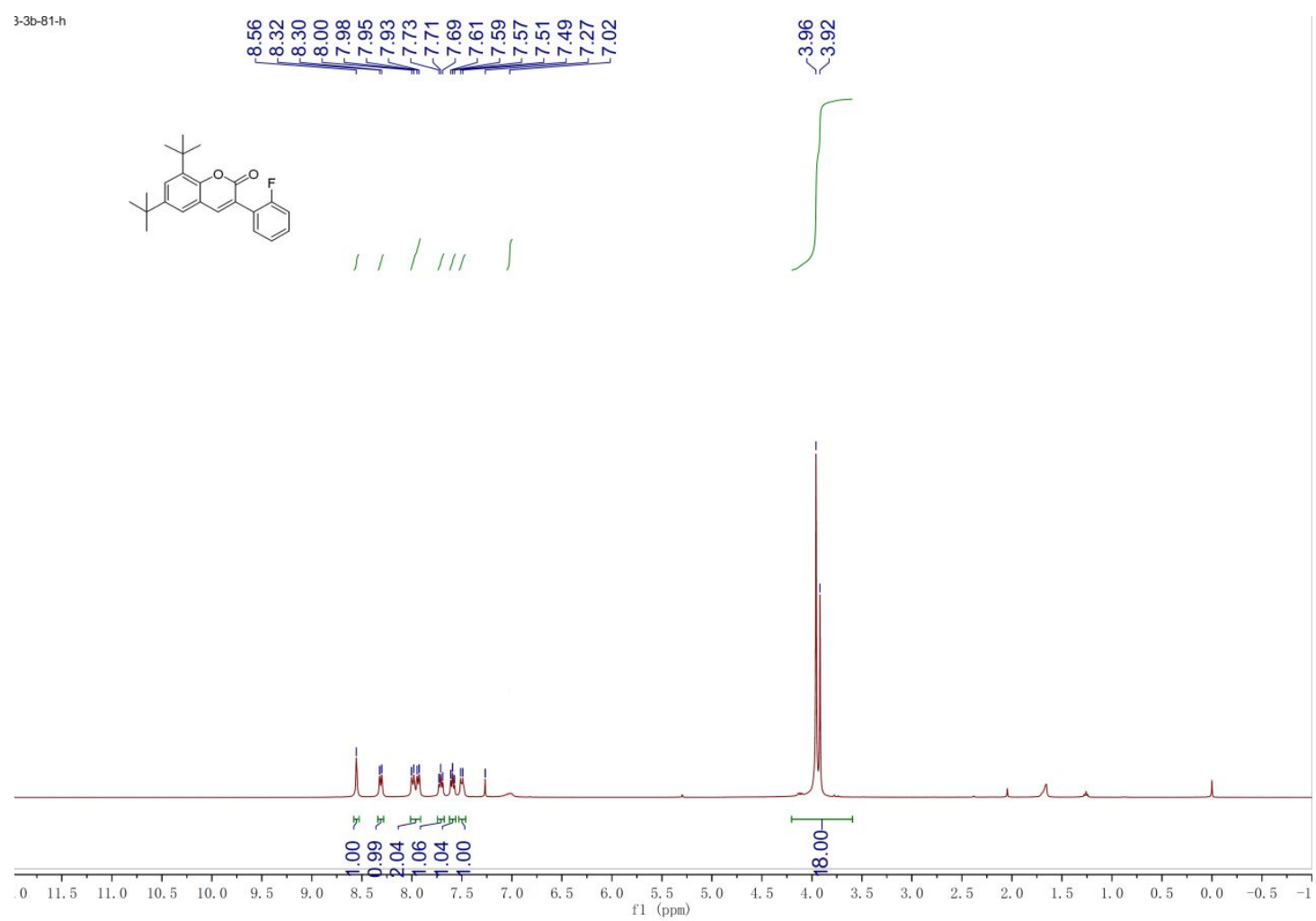

7n ${ }^{13} \mathrm{C}$ NMR $\left(100 \mathrm{MHz}, \mathrm{CDCl}_{3}\right)$ 

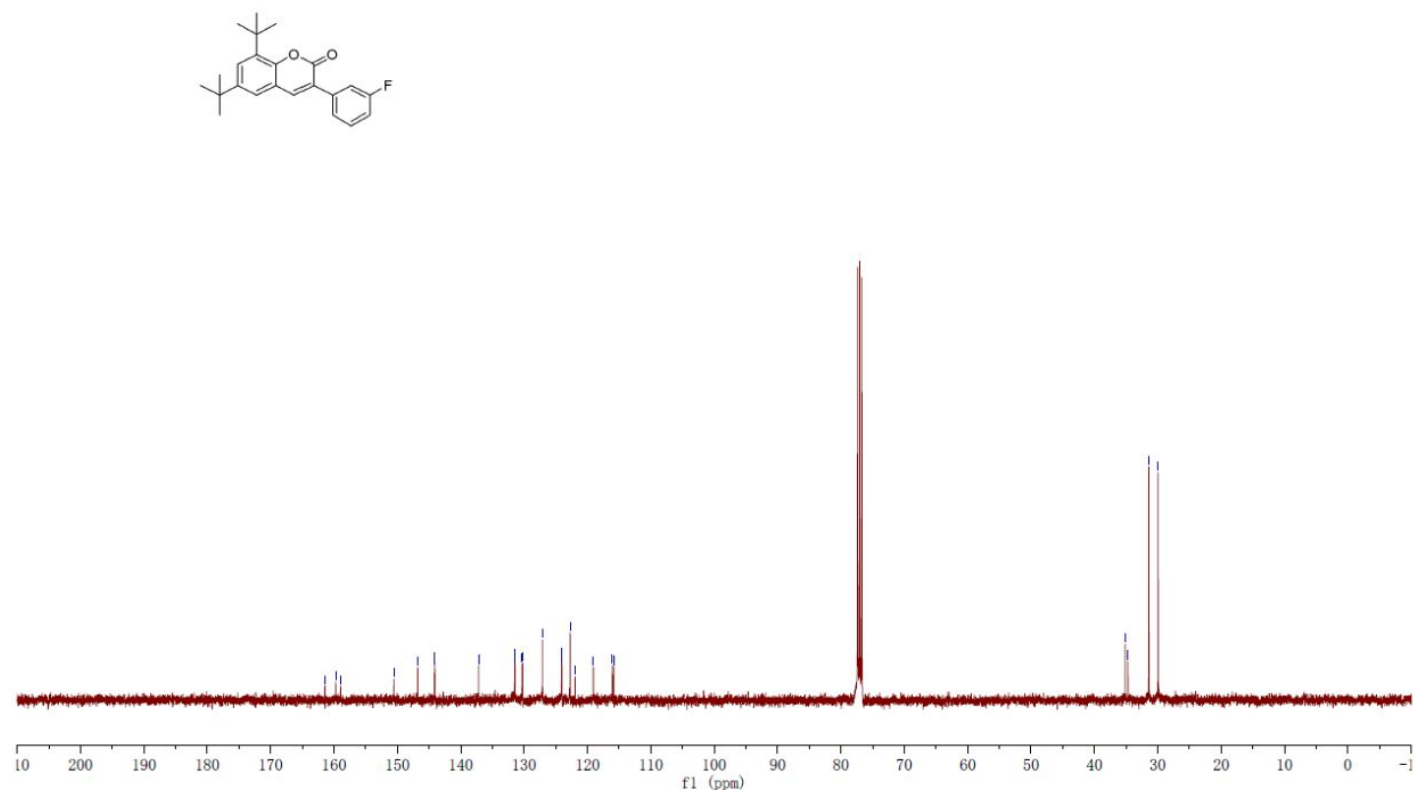
7o ${ }^{1} \mathrm{H}$ NMR (400 MHz, $\mathrm{CDCl}_{3}$ )

GZL-1-86-H
test

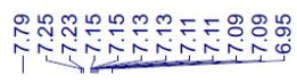

용

$\stackrel{\bullet}{i}$
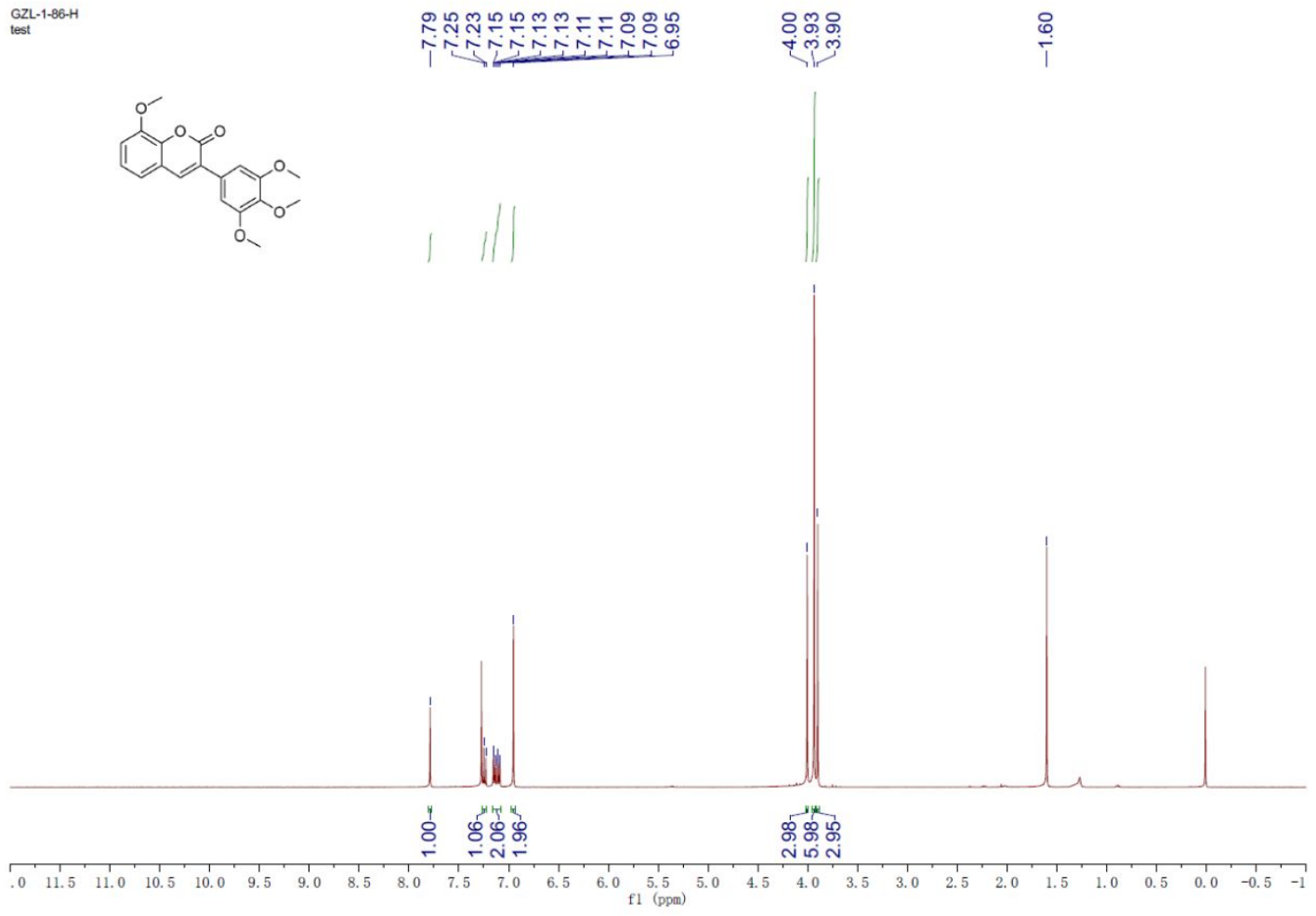

7o ${ }^{13} \mathrm{C}$ NMR $\left(100 \mathrm{MHz}, \mathrm{CDCl}_{3}\right)$
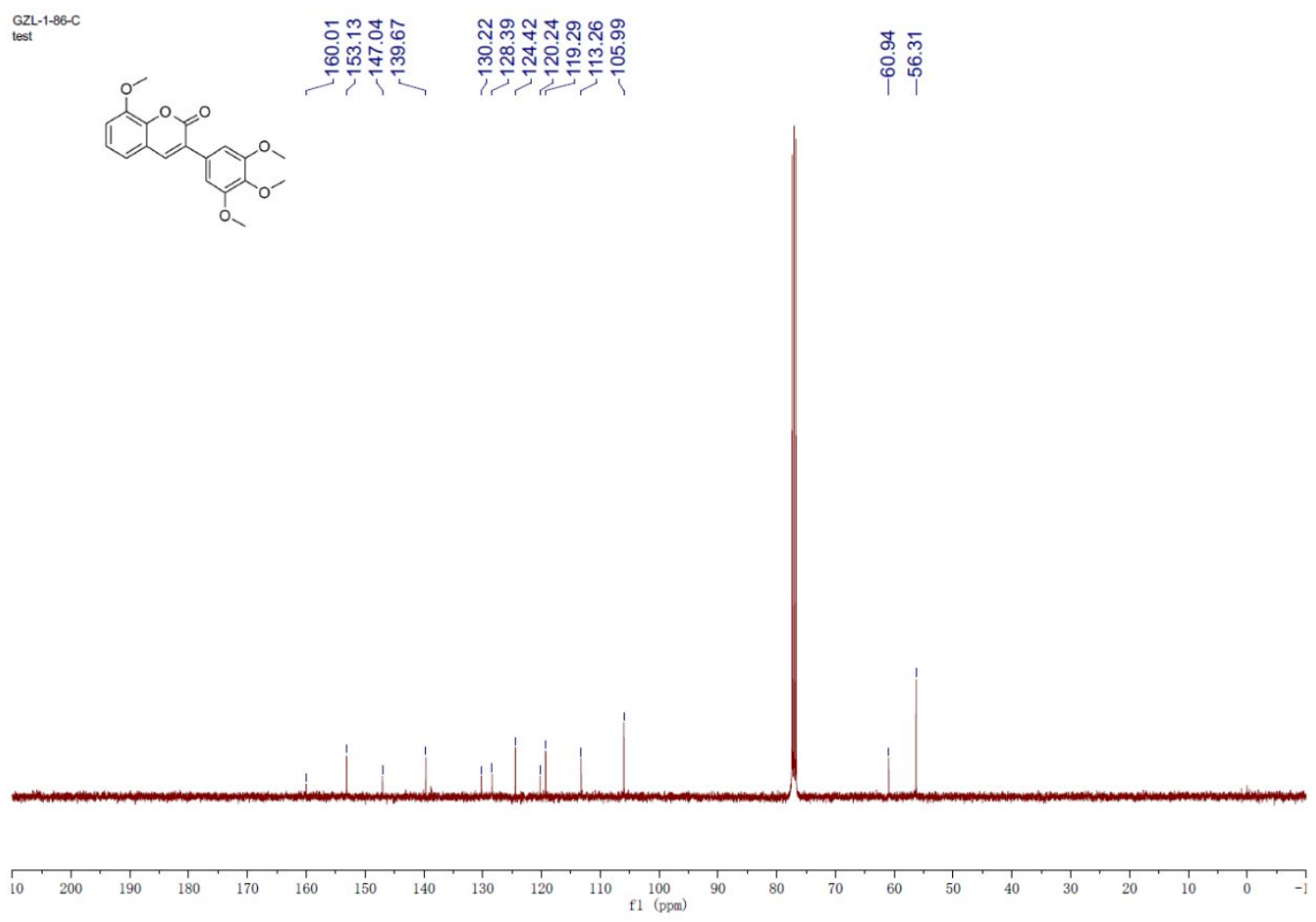

S37 
7p ${ }^{1} \mathrm{H}$ NMR $\left(400 \mathrm{MHz}, \mathrm{CDCl}_{3}\right)$

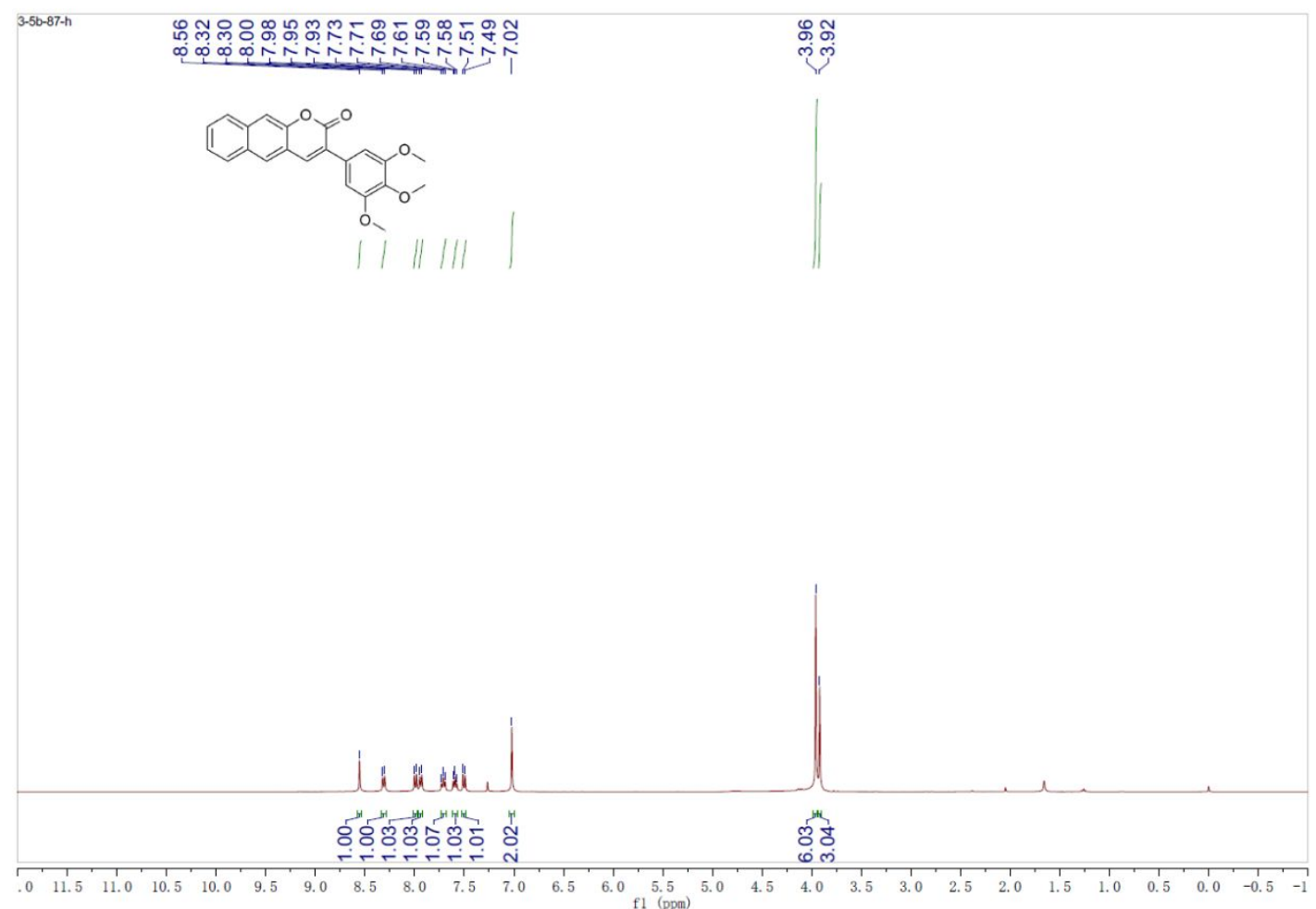

7p ${ }^{13} \mathrm{C}$ NMR $\left(100 \mathrm{MHz}, \mathrm{CDCl}_{3}\right)$

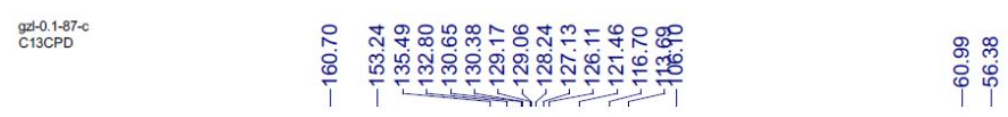

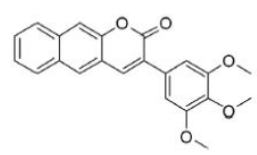

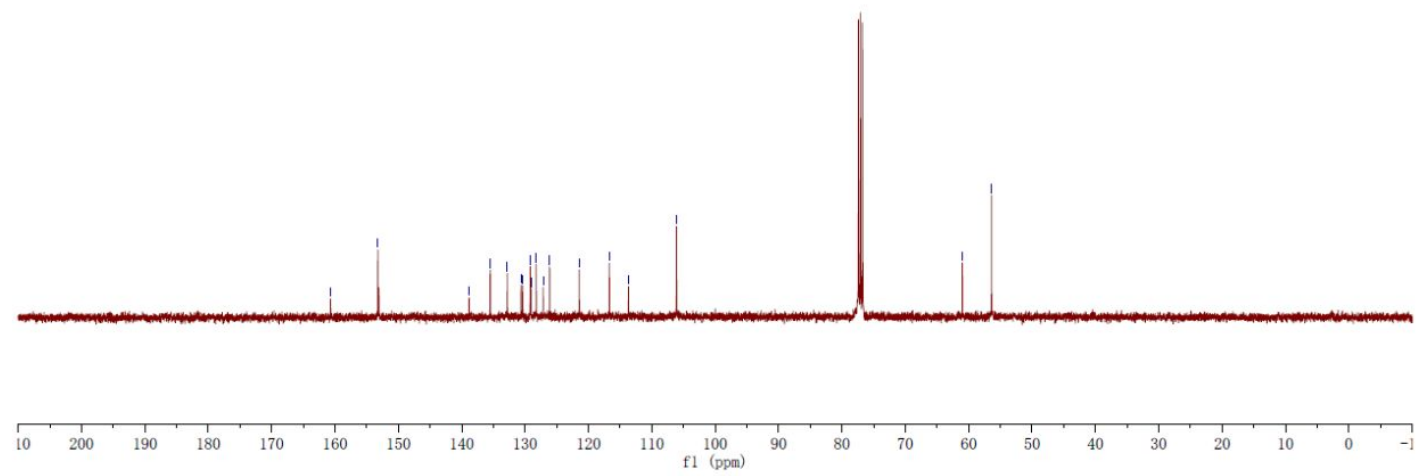


7q ${ }^{1} \mathrm{H}$ NMR (400 MHz, $\mathrm{CDCl}_{3}$ )

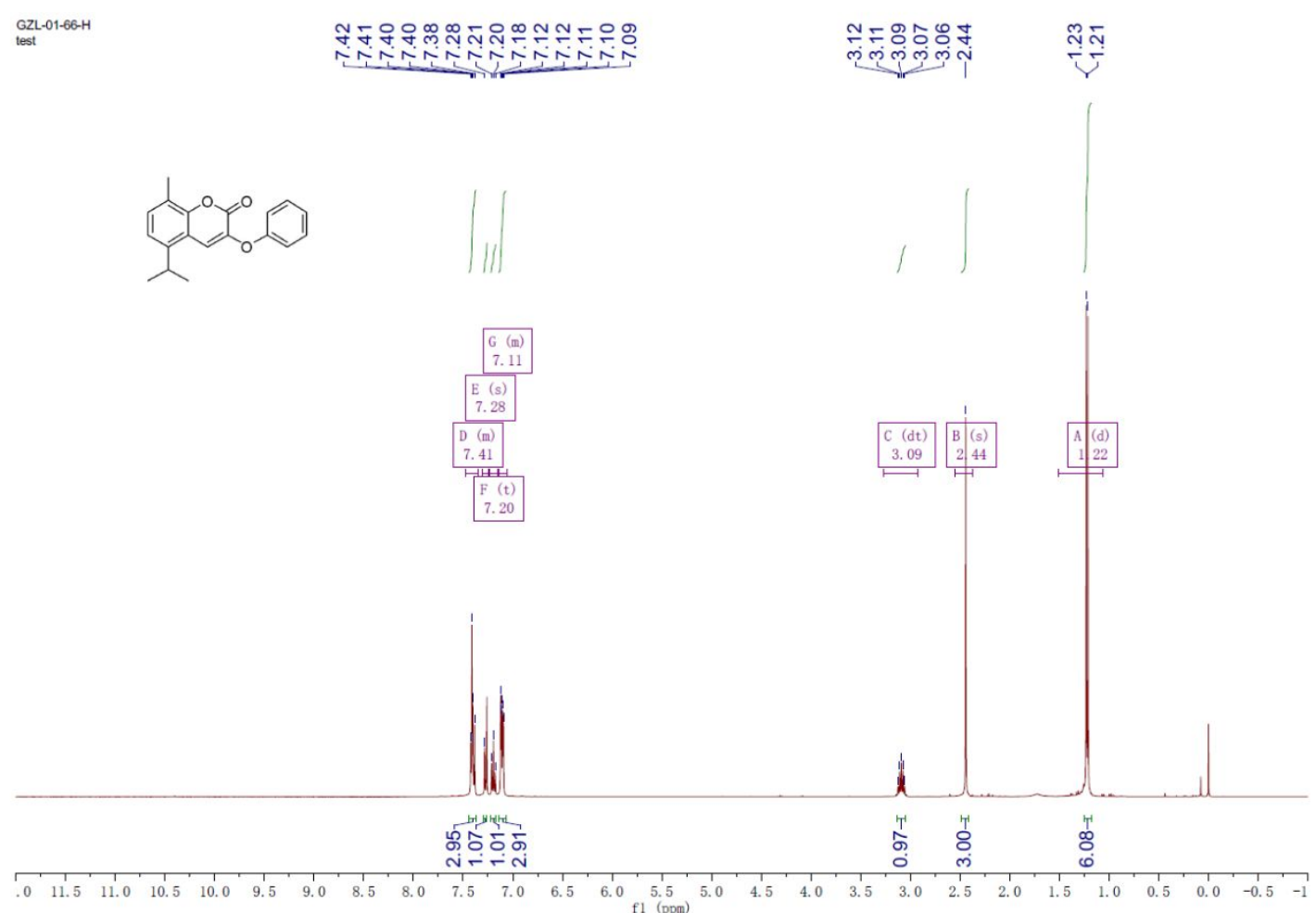

7q ${ }^{13} \mathrm{C} \mathrm{NMR}\left(100 \mathrm{MHz}, \mathrm{CDCl}_{3}\right)$

$\underset{\text { Gest }}{\text { GZ1-66-C }}$

(c)

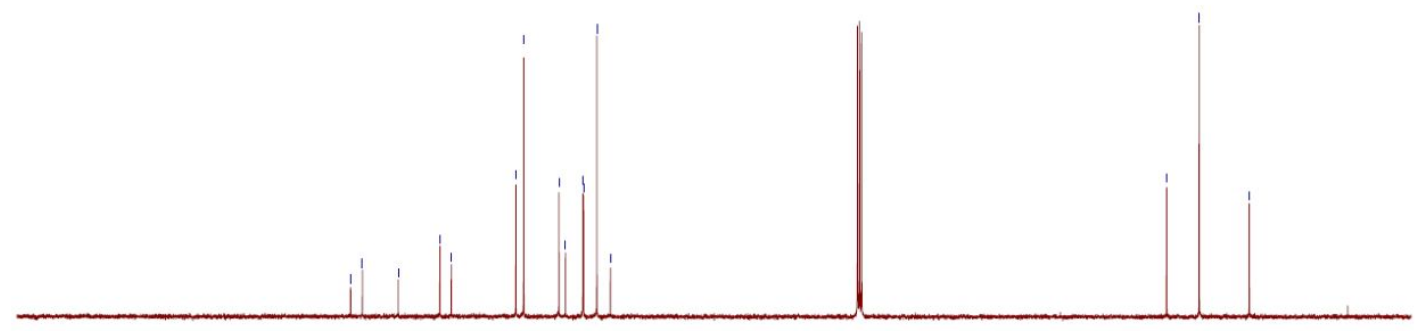

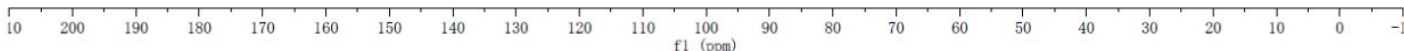




\section{Detailed bioassay procedures}

Compound solution preparation: Test compound was dissolved within a suitable amount of $N, N$-dimethyl formate and diluted with water containing $0.1 \%$ TW-80 to make a concentration of $500 \mu \mathrm{g} / \mathrm{mL}$, and the aqueous solution was diluted to 100 $\mu \mathrm{g} / \mathrm{mL}$.

Antiviral Activity of Compounds against TMV in Vitro. Fresh leaf of the 5-6 growth stage of tobacco ( $N$. tabacum L.) inoculated by the juice-leaf rubbing method (concentration of TMV was $6 \times 10^{-3} \mu \mathrm{g} / \mathrm{mL}$ ) was cut into halves along the main vein. The halves were immersed into the solution of test compounds and solvent (double-distilled water containing $0.1 \% \mathrm{TW}-80$ ) for $30 \mathrm{~min}$, respectively, and then cultured at $25{ }^{\circ} \mathrm{C}$ for $72 \mathrm{~h}$. The local lesion numbers were then counted. Each compound was replicated at least 3 times.

Protective Effect of Compounds against TMV in Vivo. The compound solution was smeared on the growing $N$. tabacum L. leaves of the same ages. Another pot was smeared with solvent for control. After $12 \mathrm{~h}$, the leaves were inoculated by the juice-leaf rubbing method and then washed with water. The local lesion numbers appearing 3-4 days after inoculation were counted. There were three replicates for each compound.

Inactivation Effect of Compounds against TMV in Vivo. The virus was inhibited by mixing with the compound solution at the same volume for $30 \mathrm{~min}$. The mixture 
was then inoculated on the growing leaves of the same ages, whereas another pot was inoculated with the mixture of solvent and the virus for control. The local lesion numbers were recorded 3-4 days after inoculation. There were three replicates for each compound.

Curative Effect of Compounds against TMV in Vivo. TMV (concentration of $6.0 \times$ $10^{-3} \mathrm{mg} / \mathrm{mL}$ ) was inoculated on the growing leaves of $N$. tabacum L. of the same ages. Then, the leaves were washed with water and dried. The compound solution was smeared on the leaves, whereas another pot was smeared with solvent for control. The local lesion numbers were then counted and recorded 3-4 days after inoculation. There were three replicates for each compound.

The in vitro and in vivo inhibition rates of the compound were then calculated according to the following formula ("av" means average, and controls were not treated with compound):

inhibition rate $(\%)=[($ av local lesion number of control - av local lesion number of drugtreated)/av local lesion number of control] $\times 100 \%$.

\section{Detailed bioassay procedures for the fungicidal activities}

The compounds were evaluated in mycelial growth tests in artificial media against 14 plant pathogens at rate of $50 \mathrm{mg} \mathrm{L}^{-1}$.

Test compound was dissolved within a suitable amount of acetone and diluted with water containing $0.1 \% \mathrm{TW}-80$ to the concentration of $500 \mathrm{mg} \mathrm{L}^{-1}$. To each petri dish was added $1 \mathrm{~mL}$ such solution and $9 \mathrm{~mL}$ culture medium to make a $50 \mathrm{mg} \mathrm{L}^{-1}$ of medicated tablet, whereas to another petri dish was added $1 \mathrm{~mL}$ sterilized water and 9 
$\mathrm{mL}$ culture medium as blank control. A diameter of $4 \mathrm{~mm}$ of hyphae was cut by a whole puncher along the hyphae for bacteria to the outer plate and moved to the medicated tablet. Each treatment was performed three times. The dishes were stored in controlled environment cabinets $\left(24 \pm 1^{\circ} \mathrm{C}\right)$ for $48 \mathrm{~h}$, after which the diameter of mycelia growth was investigated and percentage inhibition was calculated. There were three replicates for each compound.

Percentage inhibition $(\%)=$ (averaged diameter of mycelia in blank controls averaged diameter of mycelia in medicated tablets) / averaged diameter of mycelia in blank controls.

Larvicidal Activities against diamondback moth (Plutella xylostella). Stock solutions of each test compound was prepared in dimethylformamide at a concentration of $600 \mathrm{mg} \mathrm{L}^{-1}$ and then diluted to $200 \mathrm{mg} \mathrm{L}^{-1}$ with water containing TW-20. Leaf-dip method was used. Leaf discs $(5 \mathrm{~cm} \times 3 \mathrm{~cm})$ were cut from fresh cabbage leaves (or other leaves) and then dipped into the test solution for $3 \mathrm{~s}$. After air-drying, the treated leaf discs were placed individually into vertical tube (or Petri dishes) and the discs were infested with second instar larvae. Percentage mortalities were evaluated 3 days after treatment. Evaluations were based on a percentage scale of $0-100$, where 0 equals no activity and 100 equals total kill. Each treatment was performed three times. Error of the experiments was about 5\%.

Stomach Toxicity against Mythimna separata, Helicoverpa armigera, and Pyrausta nubilalis.

The stomach toxicities of the title compounds against Mythimna separata, 
Helicoverpa armigera, and Pyrausta nubilalis were tested according to the leaf-dip method using the reported procedure. Leaf disks (about $5 \mathrm{~cm}$ ) were cut from fresh corn leaves and then were dipped into the test solution for 3-5 s. After air drying, the treated leaf disks were placed individually into a glass-surface vessel $(7 \mathrm{~cm})$. Each dried treated leaf disk was infested with 10 third-instar Mythimna separata, or Helicoverpa armigera, or Pyrausta nubilalis. Percentage mortalities were evaluated 4 days after treatment. Leaves treated with acetone were provided as controls. Each treatment was performed three times. 